\title{
Complex Interaction Between CMT Equipment and Robot Controllers During the WAAM Process: Consequences for Toolpath Accuracy
}

\section{Ricardo Da Silva Viola}

Clermont Auvergne University: Universite Clermont Auvergne

\section{Xavier Balandraud ( $\nabla$ xavier.balandraud@sigma-clermont.fr)}

Clermont Auvergne University: Universite Clermont Auvergne

\section{Fabien Poulhaon}

Clermont Auvergne University: Universite Clermont Auvergne

\section{Pierre Michaud}

Clermont Auvergne University: Universite Clermont Auvergne

\section{Emmanuel Duc}

Clermont Auvergne University: Universite Clermont Auvergne https://orcid.org/0000-0002-5893-0396

\section{Research Article}

Keywords: Wire arc additive manufacturing, Path planning, Trajectory, Discontinuous deposition, Controller

Posted Date: January 20th, 2022

DOI: https://doi.org/10.21203/rs.3.rs-1243948/v1

License: (c) (i) This work is licensed under a Creative Commons Attribution 4.0 International License. Read Full License 


\title{
Complex interaction between CMT equipment and robot controllers during the WAAM process: consequences for toolpath accuracy
}

\author{
Ricardo Da Silva Viola ${ }^{1,2}$, Xavier Balandraud ${ }^{2}$, Fabien Poulhaon ${ }^{1}$, Pierre Michaud ${ }^{1}$, \\ Emmanuel Duc ${ }^{2, *}$ \\ ${ }^{1}$ Univ. Bordeaux, ESTIA Institute of Technology, F-64210 Bidart, France \\ ${ }^{2}$ Clermont Auvergne INP, Université Clermont Auvergne, CNRS, Institut Pascal, 63000 \\ Clermont-Ferrand, France
}
*Corresponding author. Tel.: +33 (0)473288096. E-mail address: emmanuel.duc@ sigma- clermont.fr

\begin{abstract}
In the WAAM process, the accuracy of the toolpath is of prime importance for the mechanical properties of the final part because of the material defects that could be generated. This paper deals with the motion analysis of the end effector nozzle of a robot dedicated to the WAAM process. The movement of the nozzle to create a rectangular layer was experimentally analyzed without physically depositing material (trajectory definition only). Various strategies, nozzle speeds and layer areas were compared in terms of travel time and length over different sections of the toolpath in order to identify various problems, in particular associated with acceleration and deceleration phases when changing direction. The consequences of a discontinuous deposition were also studied, revealing a complex interaction between cold metal transfer equipment and robot controllers. The results enable a better understanding of this interaction, which is important for deposition quality and performance. Finally, a model was proposed to calculate the manufacturing time of any layer area based on a preliminary identification for a single area.
\end{abstract}

Keyword: Wire arc additive manufacturing; Path planning; Trajectory; Discontinuous deposition; Controller 


\section{Introduction}

Wire arc additive manufacturing (WAAM) is a production process suitable for medium to large parts in the aeronautics field [1-4]. This process is characterized by high metal deposition capacity and reduced material waste, part cost and iteration time compared with standard processes [2-4]. The method consists of depositing molten metal through an electric arc between the nozzle and the already-deposited material in a sequence of two-dimensional (2D) layers using a robot to perform the movements [5]. The quality of the weld bead depends on various parameters, such as the quality of the wire, the wire feed speed (WFS), the travel speed (TS) and the heat input [1]. Weld bead geometry is controlled by optimizing the values of the deposition parameters $[1,6]$. Models can also be used to simulate the solidification process of the metal [7]. To limit high residual stresses, internal defects, porosities and lack of fusion between adjacent weld beads, it is possible to control the deposition parameters or tilt the nozzle along the trajectory [8-10]. The mechanical quality of the final part depends on the combination of all the manufacturing input parameters [5].

In the case of a robotized process, the robot's kinematic behavior along the trajectory (previously programmed to build the part) is a determining factor [11]. In particular, slowing down the robot at constant WFS can lead to too much material being added locally: the layer is no longer regular [12]. It has been established that the quality of the metal deposited is directly related to the strategy used, which makes toolpath planning of paramount interest for the WAAM process $[6,13]$. An adequate toolpath is essential to ensure that the geometry of the deposit is close to or greater than the theoretical volume to be built [14]. The literature refers to various types of strategies, such as raster-pass, zigzag, contour or spiral in relation to material health, mechanical properties (such as strength and hardness) and geometric quality (shrinkage and warpage) [15-18]. The control of the volume of material deposited is also of great importance [19]. The most commonly-used strategies to achieve a constant deposition thickness are based on equidistant path generation methods $[16,18,20]$. Toolpath planning is crucial and should be focused on the accuracy of the robot's movements in order to have a direct impact on the geometrical, material and mechanical qualities of the built part [10, 21, 22, 23].

Comments can be made about the continuous/discontinuous character of the deposition:

- When the geometry of the 2D layer allows it, metal deposition is preferably composed of several straight sections without intermediate stops or restarts [24]. This procedure, 
widely used in toolpath programming, allows the continuity of the arc, avoiding stops that usually create defects [25]. Curved sections are often broken down into linear segments when the toolpath is computed [11]. Continuous deposition may have some disadvantages due to the high heat input [26]; the latter impacts the weld bead size and by consequence the geometry of the material deposit [27]. In practice, the higher the heat input, the higher the roughness of the part (due to a higher fluidity of the meltpool and spreading of the drop) and consequently the higher the costs associated with postprocessing [11, 26, 28].

- For discontinuous deposition, a specific command (which is named arc ON/OFF for the KRC2 controller of the robot used in this study [29]) enables us to start ( $\operatorname{arc} O N)$ and stop (arc $O F F$ ) metal deposition in specific sections of the toolpath. For example, the raster-pass strategy consists of depositing the metal along straight parallel sections in the same direction (deposition being stopped between these sections). Stops and restarts are inevitable for the production of all kinds of parts, as for most rib-web structures such as flaps, wing ribs, stiffeners or landing gear ribs in aircraft and aerospace parts $[2,3$, 25]. Since these structures cannot be created with Eulerian paths, it is impossible to produce them through continuous deposition [30]. Discontinuous depositions may lead to specific problems, such as longer deposition times, local defects and material accumulation, but they are unavoidable for many part geometries [16]. It should be noted that WAAM robotic systems offer such a feature, which is necessary to stop the wire feed. In general, the robot controller manages the cold metal transfer (CMT) equipment through a sequence of commands including the deposition parameters (e.g. $\operatorname{arc} O N / O F F)$. The real-time processing of this sequential action and the management of the wire feed can induce randomness in the regularity of the weld bead deposit.

Thus the literature shows that the use of WAAM processes necessarily imposes the precise control of the material input throughout the process. For this, it is necessary to study the kinematic behavior of the robot, which generates the variations in speed and position of the end effector. In the present study, the movement of the nozzle to create of a rectangular layer was experimentally analyzed without physically depositing material (trajectory performance only). Different strategies, nozzle speeds and layer areas were compared in terms of deposition time, toolpath length and volume of "deposited" material. The consequences of discontinuous deposition (switching between $\operatorname{arc} O N$ and $\operatorname{arc} O F F$ ) were also studied. The originality of this study is to better understand the complex interaction between CMT equipment and robot 
controllers. Another objective is to propose a model to calculate the manufacturing time of any layer area from a preliminary identification for a single area.

The paper is organized as follows. Section 2 presents the experimental method used. Section 3 is dedicated to two preliminary studies on simple cases: impact of switching between arc ON and $\operatorname{arc} O F F$ during a linear trajectory at constant nominal speed; impact of a change in direction in the programmed nozzle movement. Section 4 presents and compares the results of the experimental test campaign. Finally, a manufacturing time estimation model is proposed in Section 5 .

\section{Experimental method}

A test campaign was defined to compare different strategies and analyze various output parameters such as trajectory error and duration of acceleration/deceleration phases, as well as the impact of switching between $\operatorname{arc} O N$ and $\operatorname{arc} O F F$ (reproducing a discontinuous deposition).

\subsection{Device}

Figure 1 shows some images of the experimental device. A six-axis KUKA robot (KR 100-2 HA 2000 model) and a KRC2 controller were used to control the movement of the nozzle of a CMT device (Fronius). The spatial configuration of the robot allowed free and unobstructed movement of the equipment within the inert chamber that defines the robot's workspace. The latter was such that no kinematic singularity was possible. Most of the results in this study were obtained at a nozzle altitude $z=50 \mathrm{~mm}$ from the platform, in the middle of the chamber. However, other locations in the chamber were also considered for comparison purposes; see Section 4.4 . 


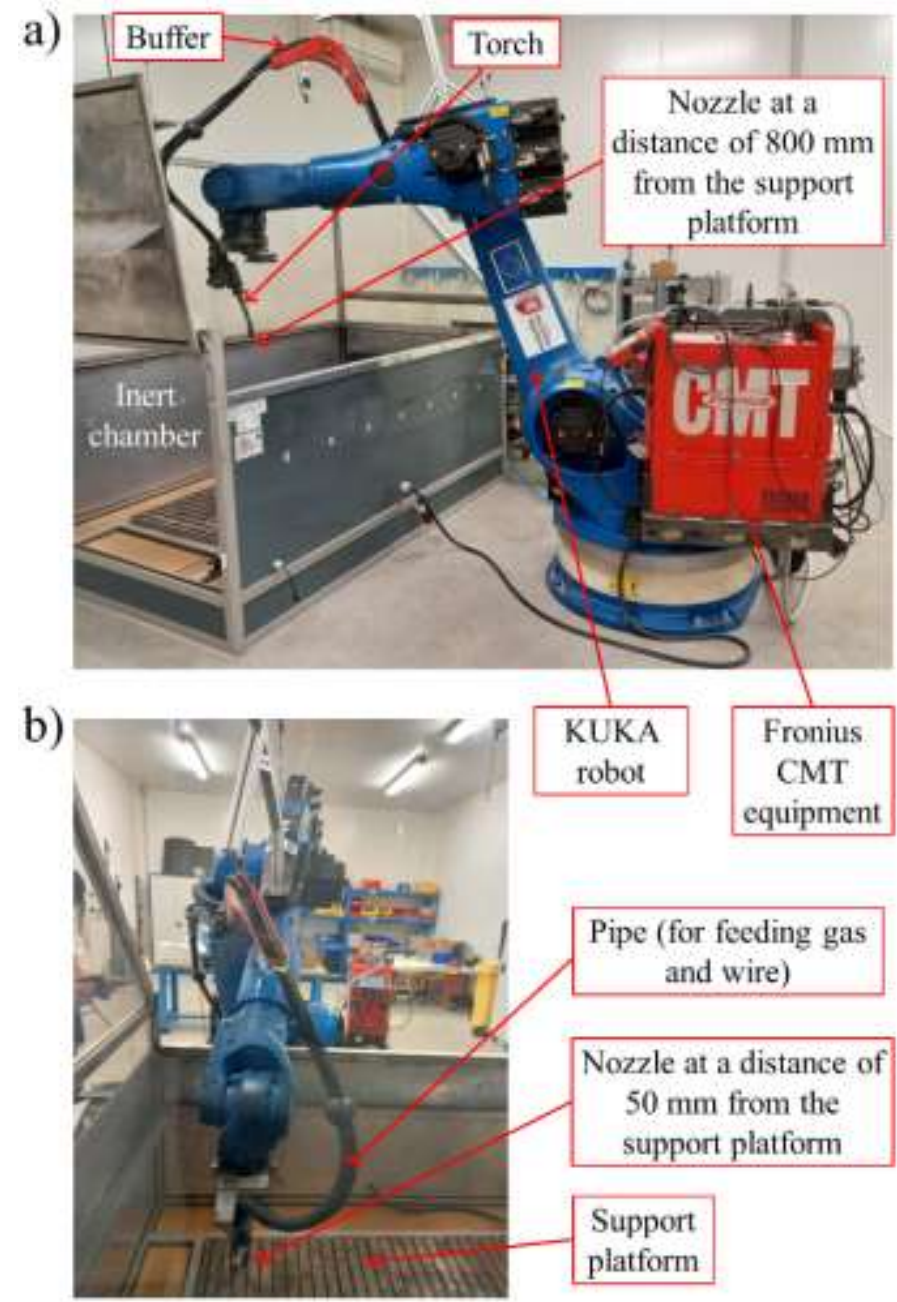

Fig. 1 Photos of the system. In the framework of this study, the nozzle movement was studied without activating the torch (trajectory definition only)

\subsection{Strategies considered}

Figure 2 presents the 8 strategies considered in the study: raster-pass, semi-circular, spiral, rectangular, swiping, as well as three triangular strategies differing in the angle of the triangles $\left(45^{\circ}, 60^{\circ}\right.$ and $\left.90^{\circ}\right)$. The blue lines represent the theoretical toolpaths of the nozzle, while the arrows indicate the travel direction. The green lines delimit a rectangular area to be theoretically filled by material deposit. This rectangle is named "objective rectangle" (OR) throughout the manuscript. We assumed a constant wire feed rate of $94.25 \mathrm{~mm}^{3} / \mathrm{s}$ to calculate the volume of deposited material. This value was defined by previous experiments, not reported here; we performed a physical deposition (namely 2209 stainless steel) with the same equipment, with a WFS of $83.335 \mathrm{~mm} / \mathrm{s}$ and a wire diameter of $1.2 \mathrm{~mm}$. It can be noted that the semi-circular and the triangular strategies included sections of toolpath outside the OR, for which the relevance 
of $\operatorname{arc} O F F$ is discussed in the present study. The spiral and rectangular strategies correspond to toolpaths remaining inside the OR, requiring thus $\operatorname{arc} O N$ over the whole toolpath. Finally, the raster-pass strategy also leads to a toolpath inside the OR, but alternating $\operatorname{arc} O N$ and $\operatorname{arc}$ OFF.
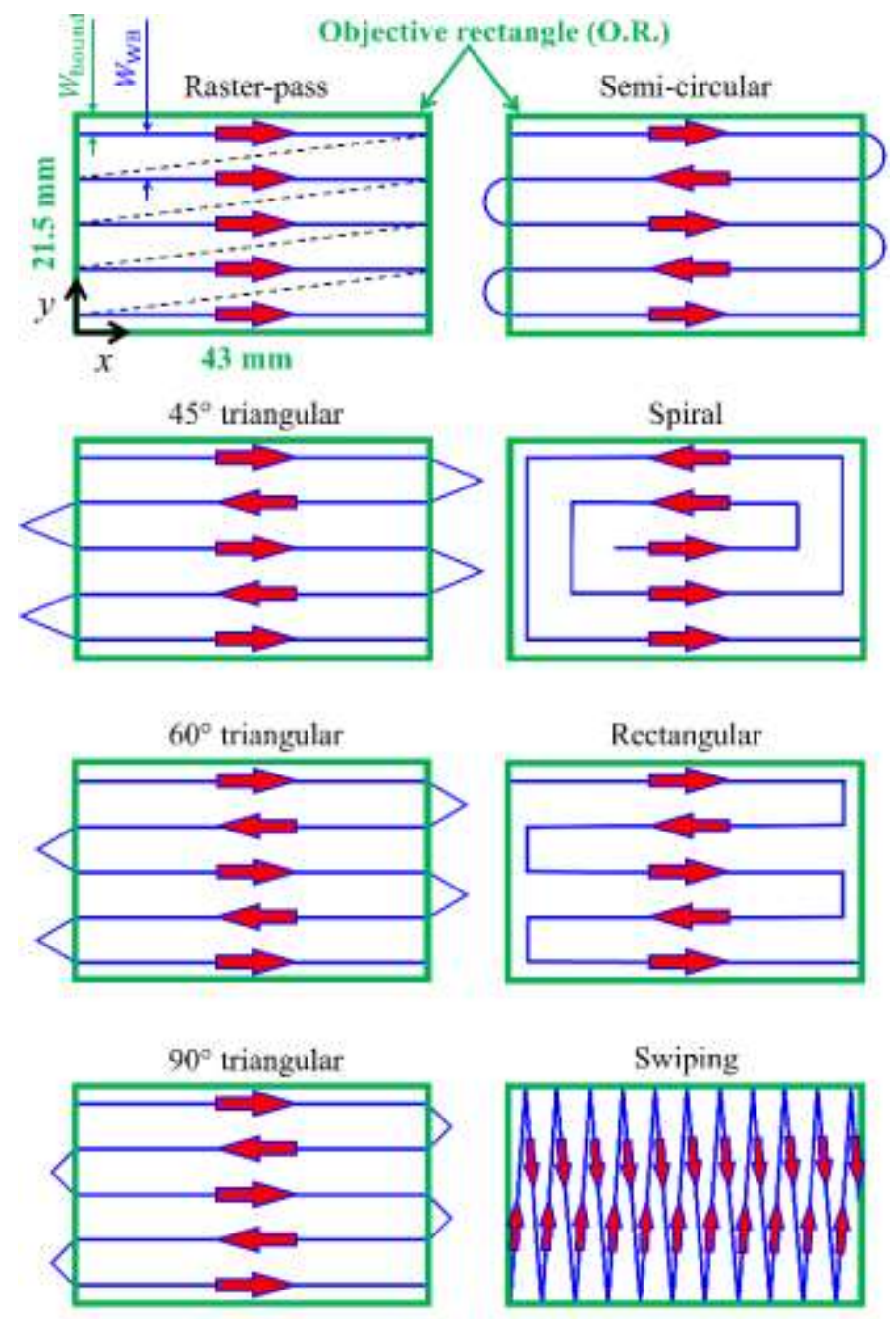

Fig. 2 Different strategies considered in the study

Two nominal travel speeds were considered in the study: $10 \mathrm{~mm} / \mathrm{s}$ and $40 \mathrm{~mm} / \mathrm{s}$. The former value corresponds to the usual value used for our experiments on 2209 stainless steel. Two OR areas of were considered: $21.5 \times 43 \mathrm{~mm}^{2}$ and $43 \times 86 \mathrm{~mm}^{2}$, sometimes referred to as "small OR" and "large OR" respectively in the following text for simplicity. It can be noted that the ratio between speeds and the ratio between areas were chosen to be the same (namely 4) for comparison purposes. The distance $W_{\mathrm{WB}}$ between the linear sections of adjacent parallel weld beads (see Fig. 2) was set to $4.43 \mathrm{~mm}$. This value was previously defined by experiments on 
2209 stainless steel. The number of horizontal weld beads $n_{\mathrm{WB}}$ was then defined from the ratio between $W_{\mathrm{WB}}$ and the width $W$ of the OR:

$$
n_{\mathrm{WB}}=\text { floor }\left(\frac{w}{W_{\mathrm{WB}}}\right)
$$

where floor $(x)$ means the nearest integer lower than $x$. The remaining distance $W_{\text {bound }}$ between the OR boundary and external depositions (see Fig. 2) can be then simply obtained by:

$$
W_{\text {bound }}=\frac{W-\left(n_{\mathrm{WB}}-1\right) \times W_{\mathrm{WB}}}{2}
$$

In fact, Equations (1) and (2) were considered to be valid if $W_{\text {bound }} \leq 0.4 W_{\mathrm{WB}}$ in order to deposit enough material at the boundary of the OR. If the inequality is not verified, $n_{\mathrm{WB}}$ must be increased by one: $n_{\mathrm{WB}} \leftarrow n_{\mathrm{WB}}+1$. The numerical application gives $n_{\mathrm{wb}}$ equal to 5 and 10 for the small and large OR, respectively, and $W_{\text {bound }}$ equal to $1.89 \mathrm{~mm}$ and $1.57 \mathrm{~mm}$, respectively.

Raw measured data were the locations $(x, y, z)$ of the nozzle as a function of time, allowing the calculation of speed, acceleration/deceleration and trajectory error in post-processing. The acquisition frequency of the $(x, y, z)$ coordinates was about $83 \mathrm{~Hz}$ (time resolution of about $12 \mathrm{~ms})$. A finite-difference scheme was used to calculate the speed, leading to a temporal resolution of about $24 \mathrm{~ms}$. Note that throughout the manuscript, unless otherwise stated, we mean by "speed" the magnitude of the speed vector. Finally, some parameters were fixed in the robot program for the whole study. In particular, the CDIS command parameter (defining the diameter around the programmed points of the trajectory through which the real trajectory must pass) was set to $5 \mathrm{~mm}$. In addition, the CVEL command parameter (playing a role in the control of the speed and acceleration of the robot) was set to $100 \%$. Changing these values would obviously modify the quantitative results described in the following of the paper, but this does not change the conclusions of the study.

Before presenting the results for the eight strategies, the next section is dedicated to preliminary observations on more elementary trajectories. 


\section{Preliminary observations}

\subsection{Impact of arc ON/OFF switching during a linear trajectory at constant nominal speed}

This section is dedicated to the case of a simple straight trajectory at constant nominal speed. Figures 3-a-1 and -b-1 present a schematic view of the two experiments performed for a trajectory of $100 \mathrm{~mm}$ (from $x=0 \mathrm{~mm}$ to $x=100 \mathrm{~mm}$ ). In the first case, the $\operatorname{arc} O N$ command is continuously activated. In the second case, a switch between $\operatorname{arc} O N$ and $\operatorname{arc} O F F$ is made at the mid-point of the trajectory. Although the nominal speed is constant, there are acceleration and deceleration phases in the actual movement of the nozzle. Figures 3-a-2 and -b-2 show the measured trajectories for a programmed nominal speed of $40 \mathrm{~mm} / \mathrm{s}$. Note that the scales of the $\mathrm{x}$ - and $\mathrm{y}$ - axes are different for readability. Whatever the $\operatorname{arc} O N / O F F$ choice, a transverse error in position ("backlash") is visible at the beginning and at the end of the toolpath: $y \approx 0.2 \mathrm{~mm}$ and $y \approx-0.1 \mathrm{~mm}$ respectively. A similar order of magnitude for the error is observed at the transition between arc $O N$ and $\operatorname{arc} O F F$ in Fig. 3-b-2. In all cases, this transverse error (along $y$ ) is associated with an acceleration/deceleration of the nozzle: see Figs 3-a-3 and -b-3 showing the variation in time of the longitudinal speed. Errors also occur at the mid-point of the trajectory when switching from arc $O N$ to $\operatorname{arc} O F F$. The nozzle stops (zero speed) when switching from $\operatorname{arc} O N$ to $\operatorname{arc} O F F$. Note that reverse switching (from $\operatorname{arc} O F F$ to $\operatorname{arc} O N$ ) also leads to similar errors; see later in this paper. The total travel time is therefore longer when changing the status of the arc ON/OFF command due to the associated stops. Consequently, an inhomogeneous deposition of material is expected, due to the variation in speed while the WFS is constant. Note finally that, except in the transient sections of the trajectory (beginning, end and middle when switching from $\operatorname{arc} O N$ to $\operatorname{arc} O F F$ ), the position error is limited to \pm 0.03 $\mathrm{mm}$, which is very low. 
a-1)

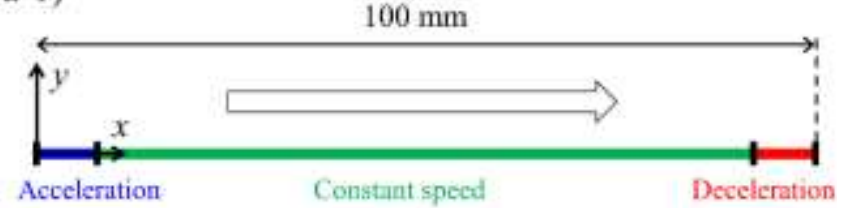

$\mathrm{a}-2)$
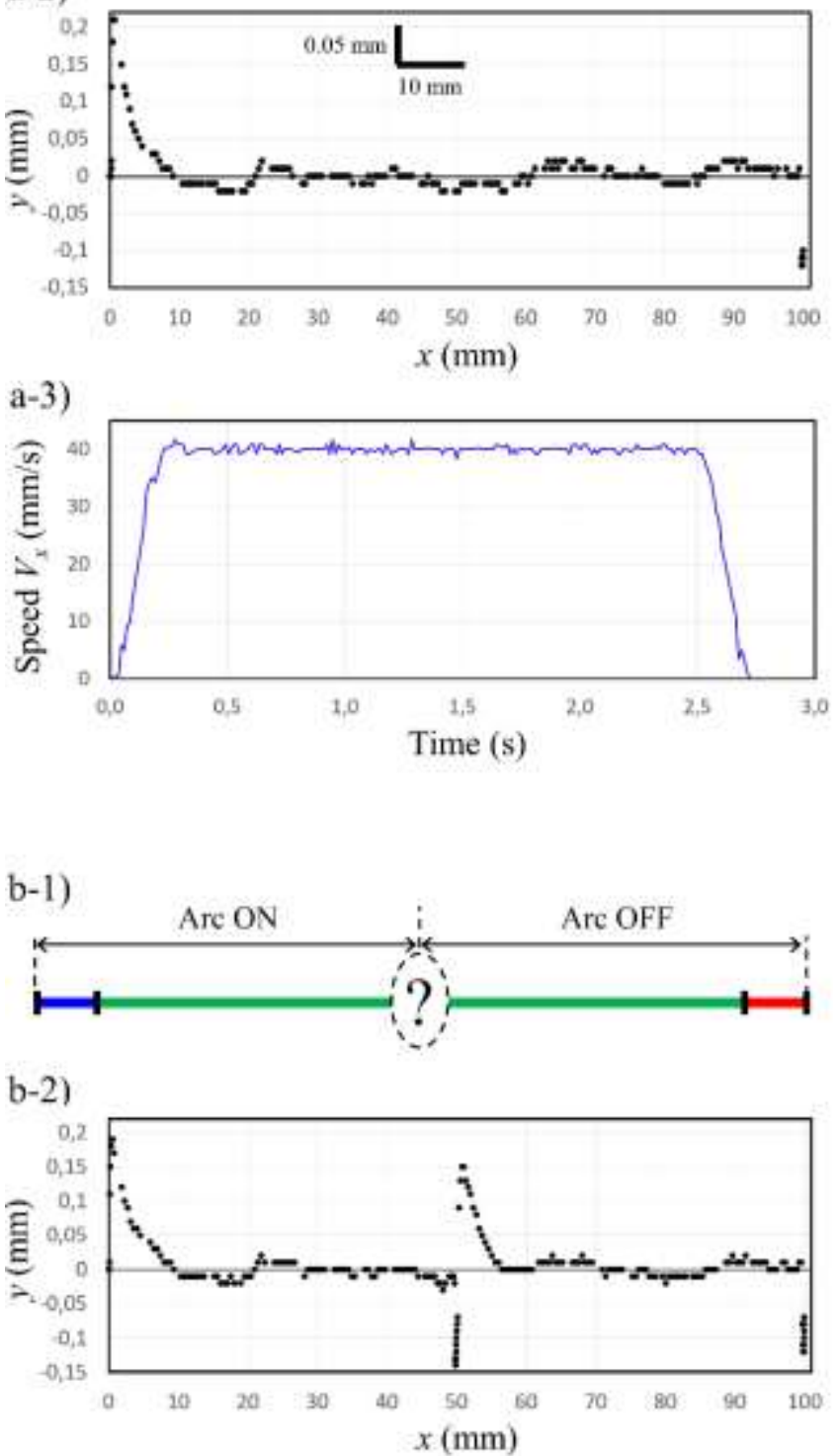

b-3)

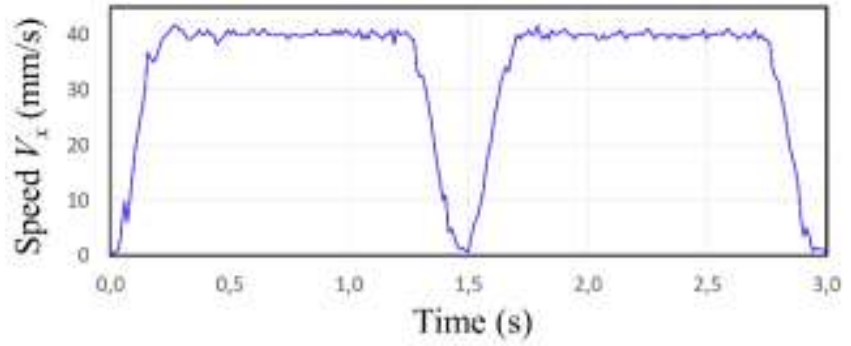

Fig. 3 Illustration of the influence of the $\operatorname{arc} O N / O F F$ command on the toolpath for a linear trajectory at a nominal speed of $40 \mathrm{~mm} / \mathrm{s}$ : a) without changing the command, b) changing $\operatorname{arc} O N$ to $\operatorname{arc} O F F$ in the middle of the trajectory 


\subsection{Impact of a change in direction}

This section deals with the influence of a sharp change in nozzle movement while the programmed nominal speed of the nozzle is constant. A sharp change induces a G1 discontinuity and does not present the progressiveness of a semi-circular toolpath. Figure 4-a illustrates the eight angles considered, namely between $2.95^{\circ}$ (angle used in the swiping strategy) to $157.5^{\circ}$ (angle used in the $45^{\circ}$ triangular strategy). Deceleration and acceleration phases are obviously expected when changing direction; for instance, Figure 4-b shows the measured toolpath for a $45^{\circ}$ angle and a nominal speed of $40 \mathrm{~mm} / \mathrm{s}$ with $\operatorname{arc} O N$ activated over the whole trajectory. The toolpath appears to be curved close to the "vertex", with a maximum trajectory error of $1.62 \mathrm{~mm}$. Figure 4-c provides the values of this error measured for the two nominal speeds $(10 \mathrm{~mm} / \mathrm{s}$ and $40 \mathrm{~mm} / \mathrm{s})$ and for the eight angles. Logically, the lower the nominal speed, the lower the trajectory error. It can be also seen that the lower the angle, the higher the error. For an angle of $2.95^{\circ}$, the error reaches $0.8 \mathrm{~mm}$ and $1.8 \mathrm{~mm}$ for $10 \mathrm{~mm} / \mathrm{s}$ and $40 \mathrm{~mm} / \mathrm{s}$ respectively, which is non-negligible. Finally, Figure 4-d gives first the average speeds measured over the whole trajectory (here about $2 \times 43 \mathrm{~mm}$ in length) for the eight angles and the two nominal speeds. Values appear to be nearly constant because the durations of the curved sections are short in comparison with the total duration. They actually slightly decrease when the angle decreases (see in particular for $40 \mathrm{~mm} / \mathrm{s}$ ). Figure 4-d secondly gives the average speeds over the curved sections only. The impact of the angle is here significant, with speed values approximately halved between an angle of $157.5^{\circ}$ and an angle of $2.95^{\circ}$. This may have significant consequences for strategies featuring numerous changes in direction, as will be discussed in Section 4.1 for the swiping strategy.

After these preliminary observations on simple cases, the next sections present the results for the different strategies presented in Section 2.2. 
a)

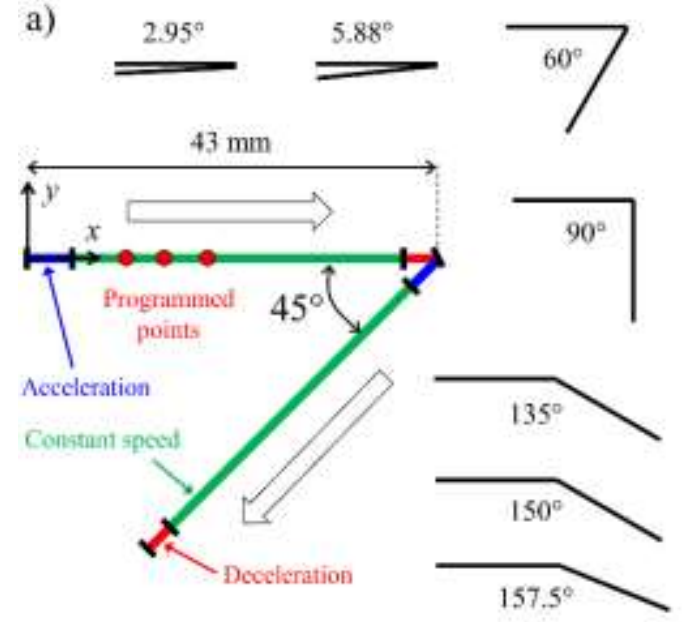

c)

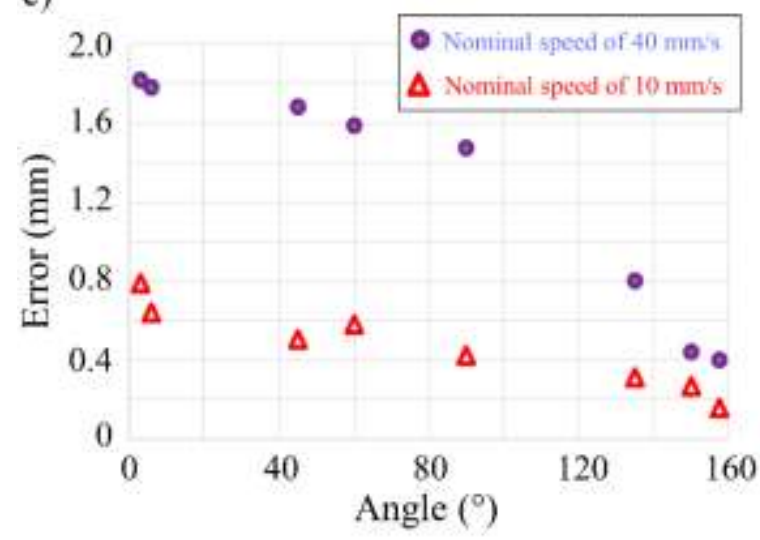

b)

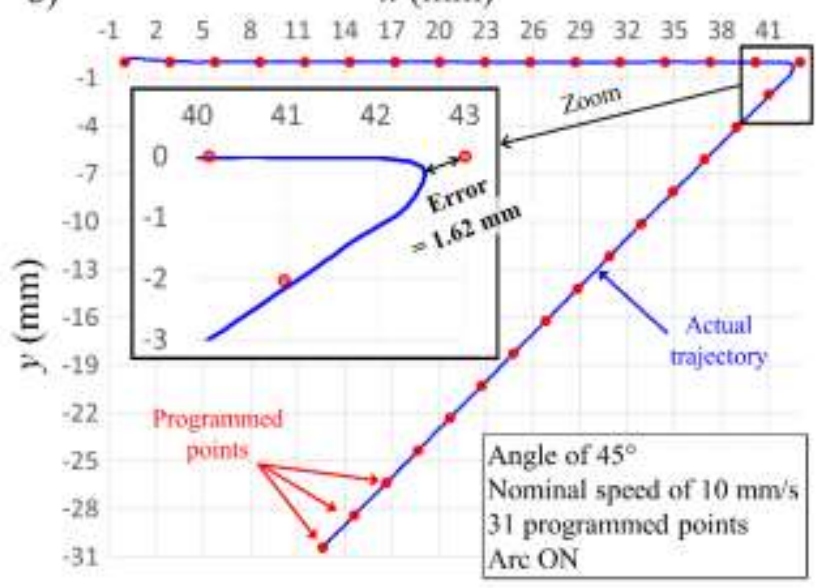

d)

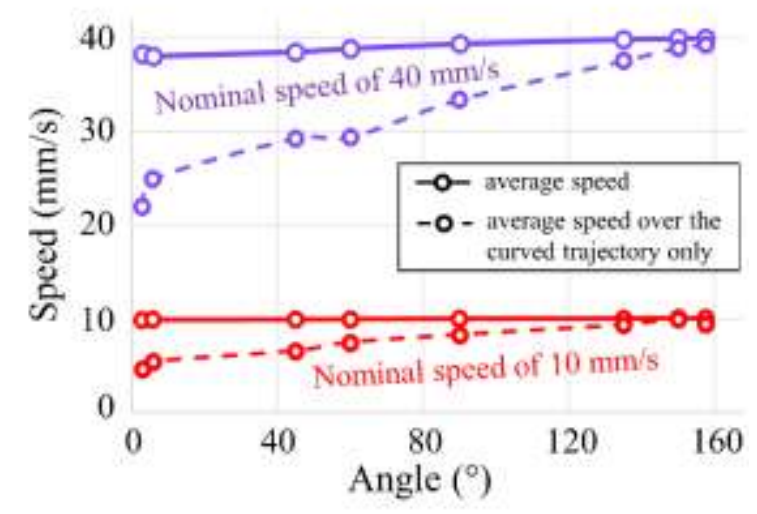

Fig. 4 Influence of the angle on a toolpath direction change: a) different angles considered and schematic representation for $45^{\circ}, \mathrm{b}$ ) example of actual toolpath and definition of the error, c) error $v s$. angle for two nominal speeds of the robot, d) actual speeds achieved by the robot

\section{Experimental results for the eight strategies}

Tables A1 and A2 in the Appendix give an overview of the results for the eight strategies in Fig. 2 and the two nominal speeds $(10 \mathrm{~mm} / \mathrm{s}$ and $40 \mathrm{~mm} / \mathrm{s})$, for the small $\left(21.5 \times 43 \mathrm{~mm}^{2}\right)$ and large $\left(43 \times 86 \mathrm{~mm}^{2}\right) \mathrm{OR}$, respectively. The total time, the total length and the total volume of deposited material (i.e. when $\operatorname{arc} O N$ is activated) are presented. Two experimental protocols are applied: with $\operatorname{arc} O N$ activated over the whole toolpath; with $\operatorname{arc} O N$ and $O F F$ inside and outside the OR respectively. The raster-pass strategy is a special case because arc ON and arc $O F F$ are both applied inside the OR, leading to "non-applicable" (N/A) indicated in certain cells of the table. Furthermore, for the rectangular, spiral and swiping strategies, cells in the column "With $\operatorname{arc} O N$ and $O F F$ " are indicated N/A because the whole toolpath remains in the 
OR. Various comments can be made when comparing the strategies. As it is not possible to present all the toolpaths and speed graphs, some comparisons have been selected in the following three sections:

- Section 4.1 compares different strategies at the nominal speed of $40 \mathrm{~mm} / \mathrm{s}$ for the small OR with arc $O N$ activated over the whole trajectory. Only one of the triangular strategies (namely $60^{\circ}$ ) is presented in the illustrations for comparison, but other angles are also discussed.

- Section 4.2 discusses the difference depending on whether or not $\operatorname{arc} O F F$ is applied outside the OR.

- Section 4.3 compares the results between the two nominal speeds and between the small and large OR. This is illustrated by the $45^{\circ}$ triangular strategy with $\operatorname{arc} O N$ activated over the whole trajectory.

\subsection{Comparison between the different strategies at a nominal speed of $40 \mathrm{~mm} / \mathrm{s}$ for the small $O R$}

Firstly, Figure 5 presents the toolpaths and the speeds for the semi-circular, $60^{\circ}$ triangular, rectangular and spiral strategies with arc $O N$ activated over the whole trajectory, for a nominal speed of $40 \mathrm{~mm} / \mathrm{s}$ and an OR of $21.5 \times 43 \mathrm{~mm}^{2}$. The red dots are the programmed points, whereas the blue curves correspond to the measured trajectories. The following comments can be made from this figure:

- As expected, all the changes in direction are accompanied by trajectory errors. This problem is significant for the quality of the WAAM process when the whole trajectory remains inside the OR (here for the rectangular and spiral strategies), because a local lack of material derives from the trajectory error. The problem is a priori not crucial when trajectory errors occur outside the OR (here for the semi-circular and $60^{\circ}$ triangular strategies), but it can be observed that small curved sections of the toolpath also exist inside the OR, at its boundaries (when entering and leaving the OR). The comparison between the three triangular strategies (not reported here) shows that this problem increases with the angle from $45^{\circ}$ to $90^{\circ}$. See later for considerations in terms of travel time.

- The time variations in nozzle speed are presented on the right side of Fig. 5. As expected, the speed decreases at each change in direction. The speed drop is of about 
$30 \%$ and $50 \%$ for the semi-circular and $60^{\circ}$ triangular strategies respectively. The comparison between the three triangular strategies (not reported here) shows that the lower the angle, the greater the speed drop. These drops are not a priori a problem as they occur mainly outside the OR (see below for considerations about the travel time). For the rectangular and spiral strategies for which the toolpath remains inside the OR, the speed drop is of about $25 \%$ at the direction changes, which is a problem for the homogeneity of the metal deposition. For all the small straight sections of the rectangular strategy as well as for the short section A-B of the spiral strategy, the robot has insufficient time to reach to the nominal speed $(40 \mathrm{~mm} / \mathrm{s})$. Decreasing the nominal speed reduces these problems, as will be seen in Section 4.3.

- Table 1 allows a comparison of the four strategies presented in Fig. 5 in terms of total length, total time and average speed. By construction, the total time is shorter for the spiral and rectangular strategies than for the semi-circular and triangular strategies (because the latter have additional path sections, outside the OR), making the former advantageous from this point of view. The lowest total time is for the spiral strategy (5.628 s), which can be explained by the shortest total length. Note that 3 decimal places for the time measurements are considered, since the time stamp is $0.012 \mathrm{~s}$ (see Section 2.2). The rectangular strategy features a slightly longer total time (5.664 s) due to the slightly longer overall length. The accuracy of the toolpath can be defined by the ratio of the total length over the programmed length. The best accuracy is obtained for the semi-circular strategy (97\%), due to the absence of sharp changes in direction (the programmed toolpath has smooth and curved transitions between the horizontal straight sections). However, the accuracies of all four strategies can be considered as being quite similar (between $95 \%$ and 97\%).

Table 1. Comparison between the semi-circular, $60^{\circ}$ triangular, rectangular and spiral strategies for a nominal speed of $40 \mathrm{~mm} / \mathrm{s}$ and small OR $\left(21.5 \times 43 \mathrm{~mm}^{2}\right)$. For the triangular strategy, arc ON was activated over the whole toolpath

\begin{tabular}{lcccc}
\hline & Semi-circular & $60^{\circ}$ triangular & Rectangular & Spiral \\
\hline Total time & $6.264 \mathrm{~s}$ & $6.456 \mathrm{~s}$ & $5.664 \mathrm{~s}$ & $5.628 \mathrm{~s}$ \\
Total length & $234.201 \mathrm{~mm}$ & $240.050 \mathrm{~mm}$ & $207.618 \mathrm{~mm}$ & $206.320 \mathrm{~mm}$ \\
Average speed & $38.573 \mathrm{~mm} / \mathrm{s}$ & $38.349 \mathrm{~mm} / \mathrm{s}$ & $37.800 \mathrm{~mm} / \mathrm{s}$ & $37.902 \mathrm{~mm} / \mathrm{s}$ \\
\hline Total "programmed" length & $242.603 \mathrm{~mm}$ & $250.437 \mathrm{~mm}$ & $217.600 \mathrm{~mm}$ & $215.710 \mathrm{~mm}$ \\
Ratio between actual and & 0.97 & 0.96 & 0.95 & 0.96 \\
programmed lengths & & & & \\
\hline
\end{tabular}



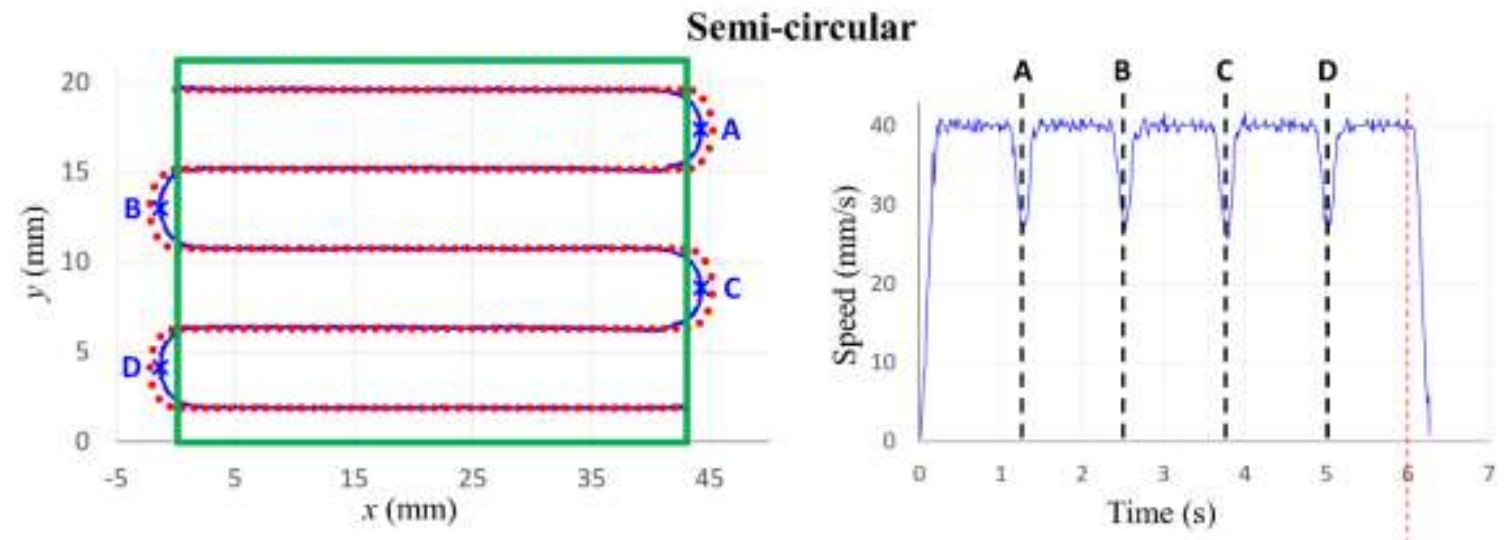

$60^{\circ}$ triangular
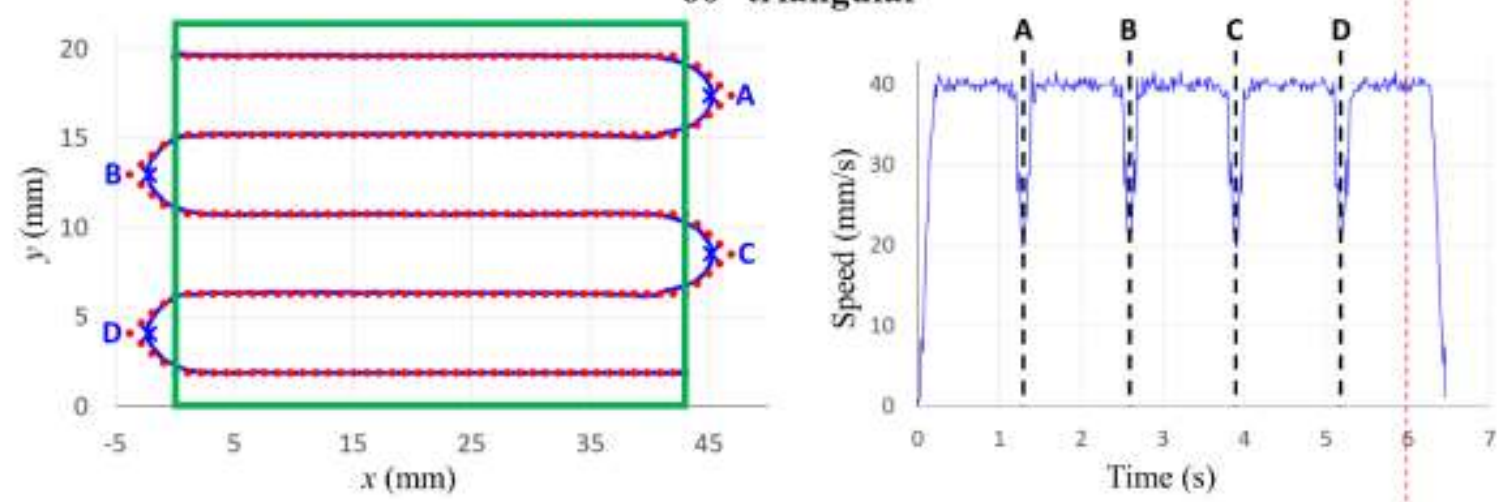

Rectangular
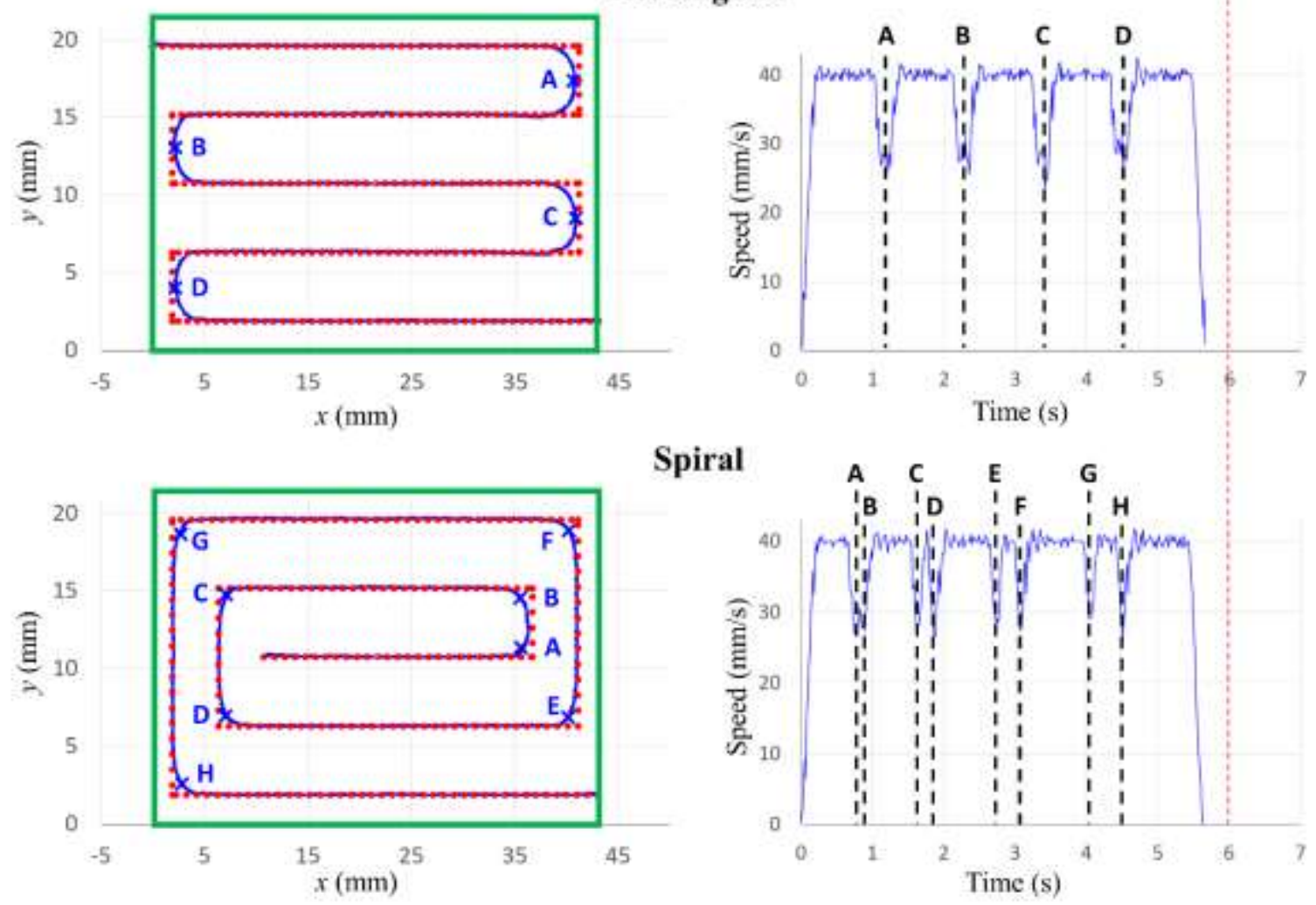

Fig. 5 Toolpath and speed for the semi-circular, rectangular and spiral strategies, as well as for one of the triangular strategies (namely $60^{\circ}$ ). The nominal speed was set to $40 \mathrm{~mm} / \mathrm{s}$ and $\operatorname{arc} O N$ was activated over the whole of each trajectory 
Secondly, Figure 6 compares the raster-pass and swiping strategies, still for a nominal speed of $40 \mathrm{~mm} / \mathrm{s}$ and an OR of $21.5 \times 43 \mathrm{~mm}^{2}$. In addition to the trajectories and speeds, the figure also provides the variation in volume of deposited material (assuming a constant wire feed rate of $94.25 \mathrm{~mm}^{3} / \mathrm{s}$ as indicated above) as a function of time and distance travelled. The following remarks can be made with respect to this figure:

- The sharp changes in direction lead to significant speed drops (see Figs 6-a-2 and -b-2): a drop of $100 \%$ and about $80 \%$ for the raster-pass and swiping strategies respectively. For the swiping strategy, this is accompanied by large trajectory errors of about $1.8 \mathrm{~mm}$ at the direction changes: see Fig. 6-b-1.

- Figures 6-a-3 and -b-3 show the variation in time of the volume of deposited material. Plateaus are obviously present when $\operatorname{arc} O F F$ is activated; however, when plotting the volume of material as a function of the distance travelled, negative consequences of the speed drops are visible: see zooms in Figs 6-a-4 and -b-4. The order of magnitude of the volume "jumps" is the same for the two strategies (about $7 \mathrm{~mm}^{3}$ ).

- Table 2 enables a global comparison of the two strategies. The programmed and actual lengths as well as the volume of deposited material are higher for the swiping strategy than for the raster-pass strategy. This is due to the numerous weld bead overlap zones in the former case. The raster-pass strategy presents an accuracy (defined above as the ratio between total actual length and total programmed length) of 0.998 . This good ratio is due to the fact that this strategy involves switches between $\operatorname{arc} O N$ and $\operatorname{arc} O F F$ at the beginning and end of each straight section: thus, the nozzle accurately reaches the end of each straight section (albeit while stopping). On the contrary, for the sweeping strategy, accuracy can be considered as low (length ratio of 0.89 ). This is due to an accumulation of trajectory error at each change in direction. Although over a much longer programmed length (464.246 $\mathrm{mm}$ compared to $387.910 \mathrm{~mm}$ ), the total time for the swiping strategy is only slightly longer than that of the raster-pass strategy (12.036 s compared with $11.580 \mathrm{~s}$ ). This is due to the time "lost" when switching between arc $O N$ and $\operatorname{arc} O F F$ in the latter case. 


\section{Raster-pass}

a-1)

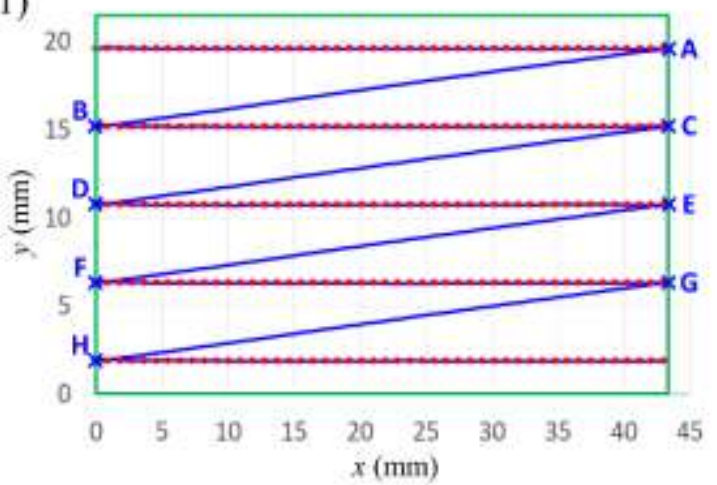

a-2)

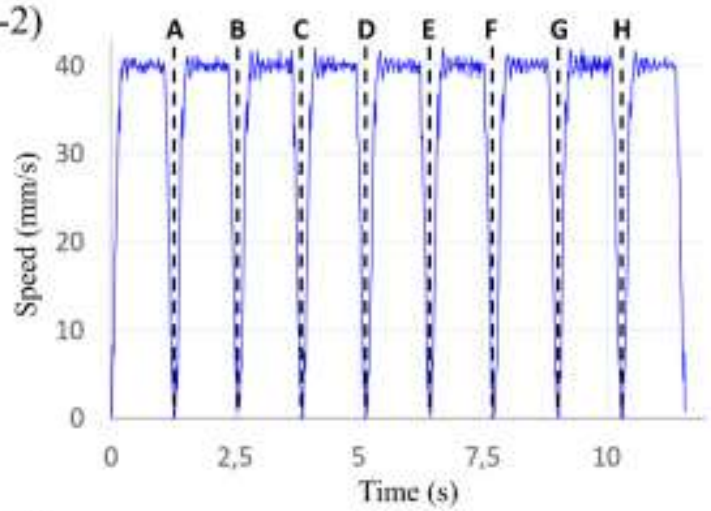

a-3)

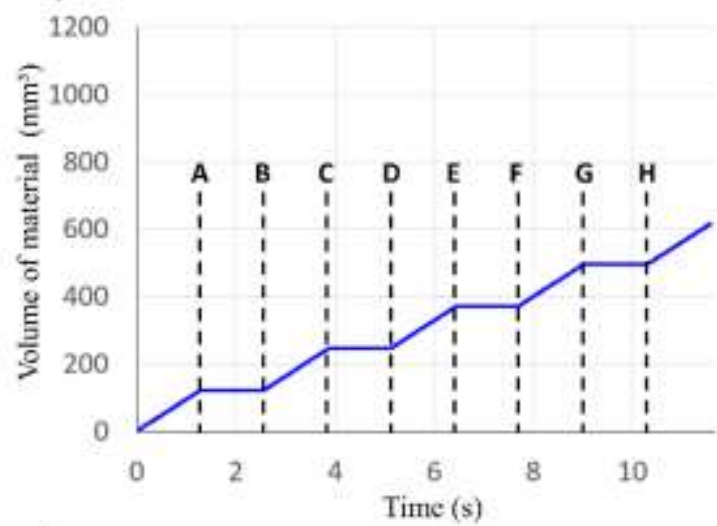

a-4)

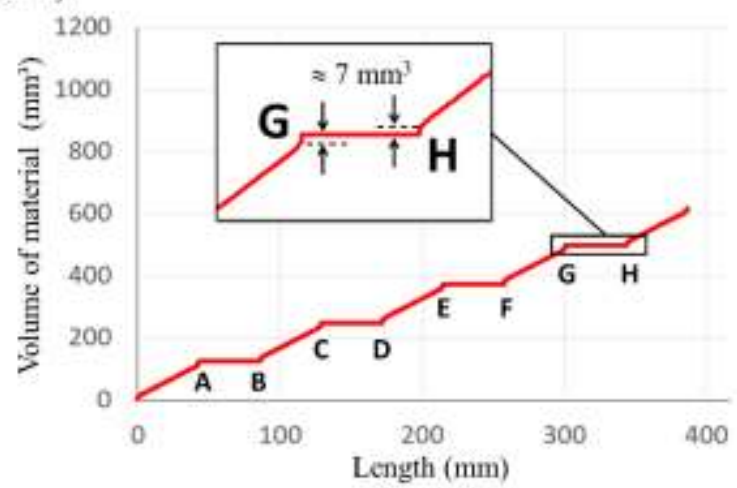

Swiping

b-1)

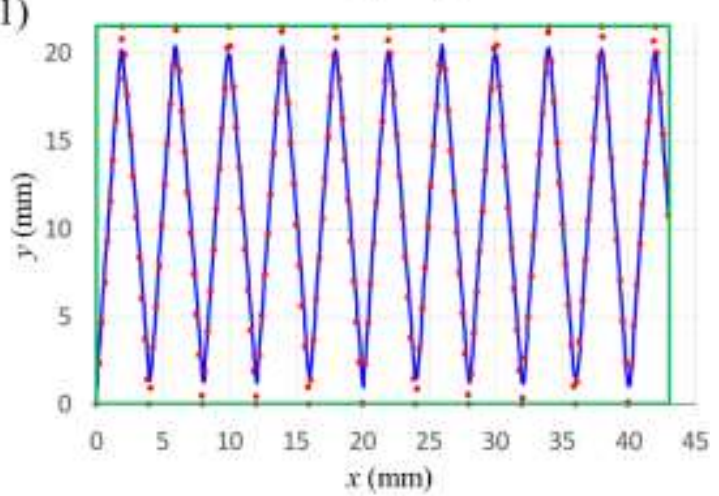

b-2)

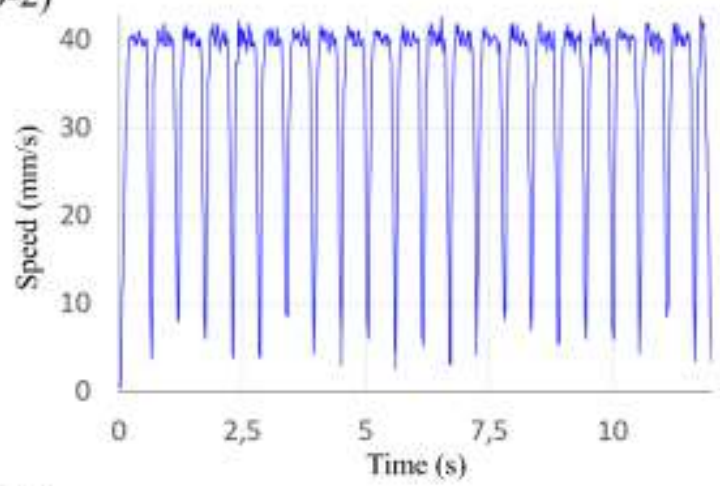

b-3)

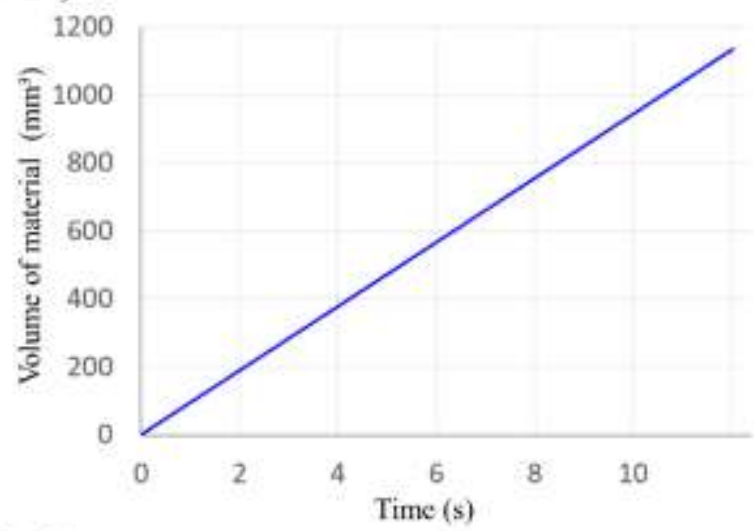

b-4)

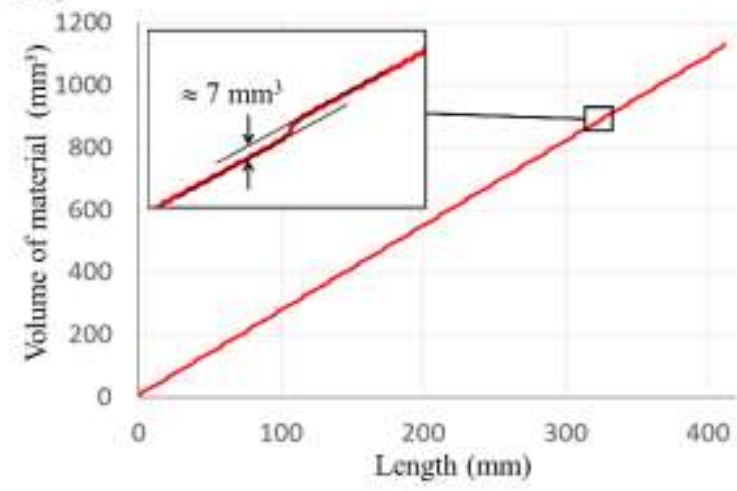

Fig. 6 Trajectory, speed and volume of materials for the raster-pass and swiping strategies, with a nominal speed of $40 \mathrm{~mm} / \mathrm{s}$ 
Table 2. Comparison between raster-pass and swiping strategies for a nominal speed of $40 \mathrm{~mm} / \mathrm{s}$ and small OR $\left(21.5 \times 43 \mathrm{~mm}^{2}\right)$

\begin{tabular}{lcc}
\hline & Raster-pass & Swiping \\
\hline Total time & $11.580 \mathrm{~s}$ & $12.036 \mathrm{~s}$ \\
Total length & $386.971 \mathrm{~mm}$ & $411.509 \mathrm{~mm}$ \\
Average speed & $33.752 \mathrm{~mm} / \mathrm{s}$ & $34.725 \mathrm{~mm} / \mathrm{s}$ \\
Volume of material deposited & $615.133 \mathrm{~mm}^{3}$ & $1134.389 \mathrm{~mm}^{3}$ \\
\hline Total "programmed" length & $387.910 \mathrm{~mm}$ & $464.246 \mathrm{~mm}$ \\
Ratio between actual and programmed lengths & 0.998 & 0.89 \\
\hline
\end{tabular}

\subsection{Difference depending on whether or not arc OFF is applied outside the OR}

The objective of this section is to discuss the relevance of applying arc OFF outside the OR. First, Figure 7 illustrates the differences using a specific case for illustration purposes: the $45^{\circ}$ triangular strategy at a nominal speed of $40 \mathrm{~mm} / \mathrm{s}$ for an OR of $21.5 \times 43 \mathrm{~mm}^{2}$. Figures $7-\mathrm{a}-1$ and -b-1 show the toolpath in the two cases. The red and black dots correspond to the programmed points with arc $O N$ and $\operatorname{arc} O F F$ respectively. The blue curves are the measured toolpaths as in the previous figures. Some comments can be made:

- the trajectory error is much higher outside the OR when $\operatorname{arc} O F F$ is activated (Fig. 7-a1). When switching from $\operatorname{arc} O N$ to $\operatorname{arc} O F F$, the speed drops to zero at times A, C, E and G (Fig. 7-a-2). Just after A, C, E and G, the speed is increased without reaching the nominal speed of $40 \mathrm{~mm} / \mathrm{s}$ due to the transition from $\operatorname{arc} O F F$ to $\operatorname{arc} O N$ at times B, D, $\mathrm{F}$ and $\mathrm{H}$. The nozzle stops were already observed in Section 3.1. The robot seems to correct the delay by cutting the programmed toolpath according to the programmed tolerance. One explanation may be that stopping the nozzle causes the robot axes to physically stop, while the controller continues to follow the programmed path. In this case, the actual path is caught up when the robot axes are released. The resulting speed law is thus a combination of the kinematic behavior of the robot and the interaction between CMT equipment and robot controllers. The delays (acceleration and deceleration times) due to arc ON/OFF switching appear to be compensated for by a shorter toolpath outside the OR.

- The speed reductions when $\operatorname{arc} O N$ is activated over the whole trajectory (Fig. 7-b-2) are of higher amplitudes than those observed for the $60^{\circ}$ triangular strategy in Fig. 5: the smaller the angle, the greater the speed drop. 
- As in Section 4.1, variations in the volume of deposited material assuming a constant WFS are displayed in Figs 7-a-3 and -b-3 as a function of time, and in Figs 7-a-4 and b-4 as a function of the distance travelled. The order of magnitude of the volume "jumps" are the same for the two strategies (about $7 \mathrm{~mm}^{3}$ ), but it is less problematic when $\operatorname{arc} O N$ is activated over the whole trajectory because it occurs outside the OR (see Figs. 7-b-1 and -b-4).

Table 3 provides a quantitative comparison showing various output parameters. Times and lengths were measured over different phases of the trajectory: constant speed in the OR, acceleration in the OR; deceleration in the OR; inside the OR; outside the OR; and over the whole toolpath. It can be noted that a "total time with arc OFF inside the OR" is indicated, which may appear strange because, in theory, arc $O F F$ is activated only when reaching the boundary of the OR. Indeed, (small) time shifts are observed in the application of the arc ON/OFF command. The following comments can be made from the table:

- When $\operatorname{arc} O N$ is activated over the whole trajectory, the time of the whole toolpath is shorter (6.732 s to be compared with $7.932 \mathrm{~s})$, which is advantageous for productivity. Moreover, the total time at constant speed inside the OR is longer (4.632 s compared to $4.380 \mathrm{~s}$ ), which is a priori better in terms of deposition quality inside the OR.

- The same remarks can be made about the lengths, but differences can be highlighted about the times outside the OR. To make up for the delay due to the activation of the arc OFF command, the toolpath length is in practice much shorter (see Fig. 7-a-1). This leads to shorter lengths outside the OR (19.474 mm, compared to $34.920 \mathrm{~mm}$ ).

- The total time with " $\operatorname{arc}$ OFF inside the OR" is $0.156 \mathrm{~s}$, which corresponds to about $2 \%$ of the duration of the whole toolpath (7.932 s). This can be considered as a nonnegligible parasitic effect in the case of large mechanical parts. 

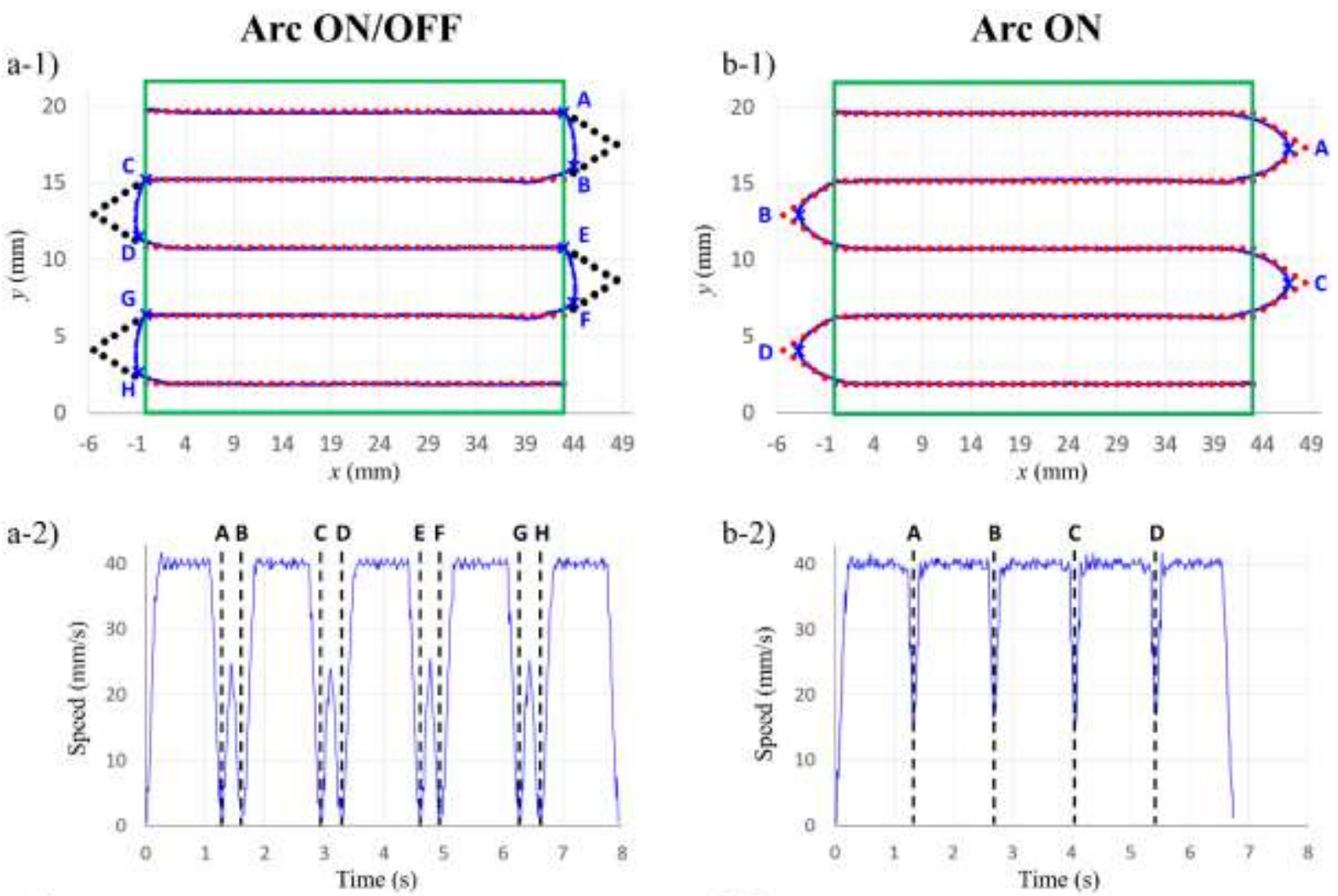

a-3)

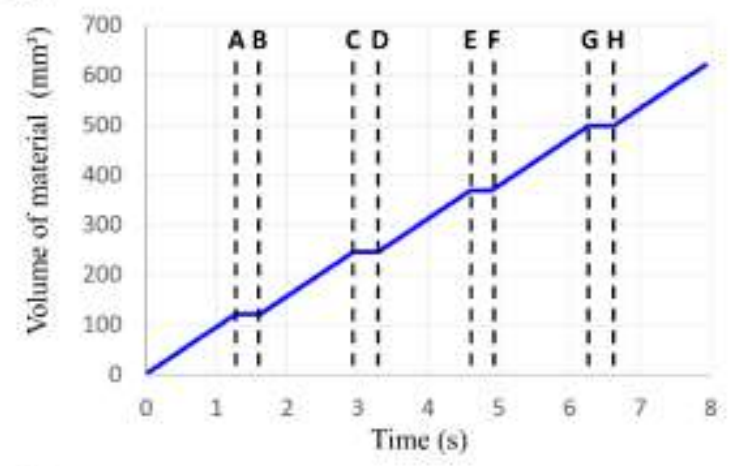

b-3)
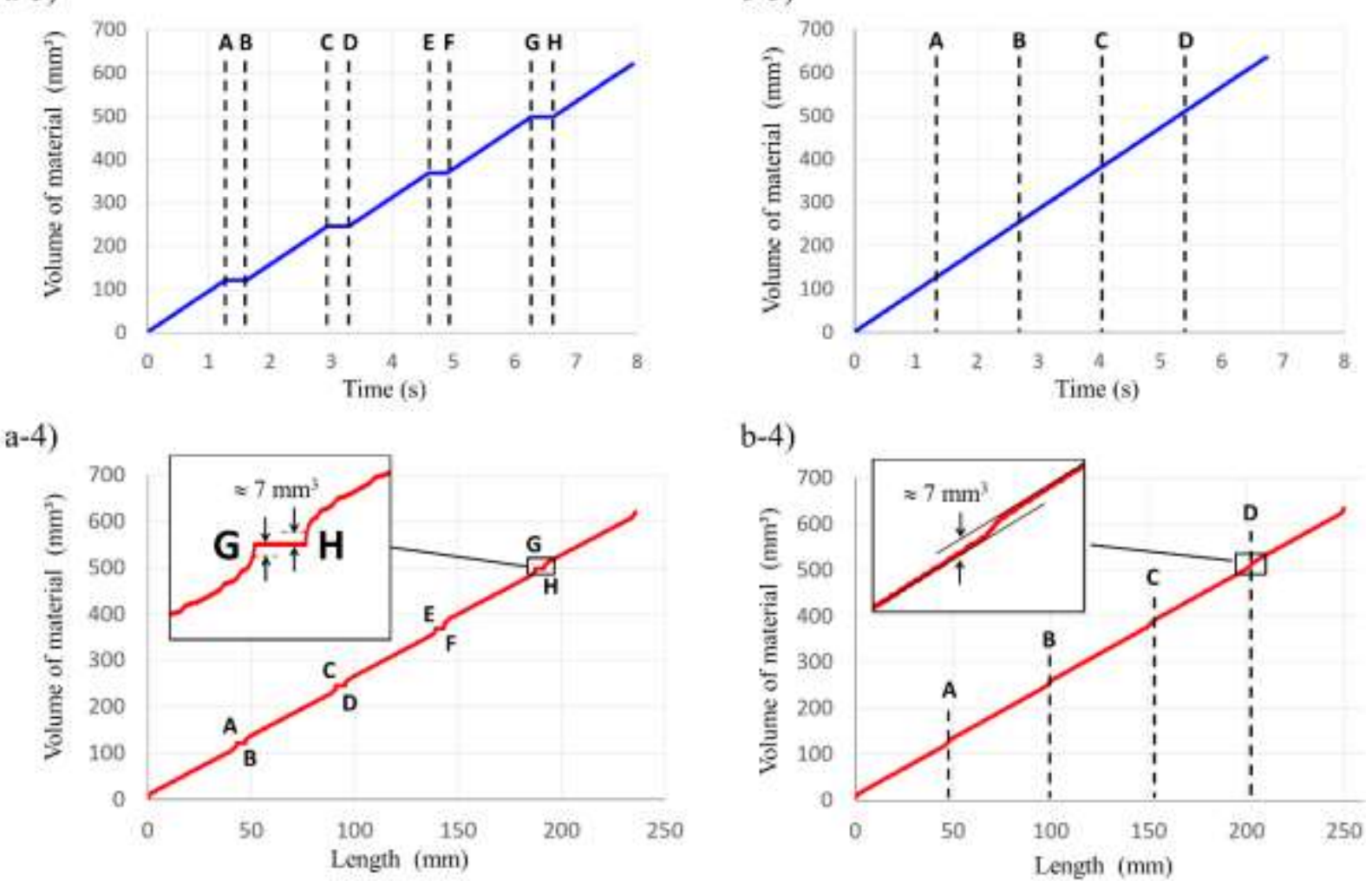

Fig. 7 Influence of the $\operatorname{arc} O N / O F F$ command on the trajectory for the $45^{\circ}$ triangular and a nominal speed of $40 \mathrm{~mm} / \mathrm{s}$ : a) with $\operatorname{arc} O N$ and $O F F$ inside and outside the objective rectangle respectively, b) with $\operatorname{arc} O N$ activated over the whole toolpath 
Table 3. Influence of the arc ON/OFF command for the $45^{\circ}$ triangular strategy, with a nominal speed of $40 \mathrm{~mm} / \mathrm{s}$ and small OR $\left(21.5 \times 43 \mathrm{~mm}^{2}\right)$

\begin{tabular}{|c|c|c|c|}
\hline & & $\begin{array}{l}\text { With } \operatorname{arc} O F F \\
\text { outside the OR }\end{array}$ & $\begin{array}{c}\text { With } \operatorname{arc} O N \text { over the } \\
\text { whole toolpath }\end{array}$ \\
\hline \multirow[t]{7}{*}{ Total time } & at constant speed in the OR & $4.380 \mathrm{~s}$ & $4.632 \mathrm{~s}$ \\
\hline & of acceleration in the OR & $0.780 \mathrm{~s}$ & $0.468 \mathrm{~s}$ \\
\hline & of deceleration in the $\mathrm{OR}$ & $0.972 \mathrm{~s}$ & $0.480 \mathrm{~s}$ \\
\hline & with $\operatorname{arc} O F F$ inside the OR & $0.156 \mathrm{~s}$ & N/A \\
\hline & inside the OR & $6.288 \mathrm{~s}$ & $5.580 \mathrm{~s}$ \\
\hline & outside the OR & $1.644 \mathrm{~s}$ & $1.152 \mathrm{~s}$ \\
\hline & of the whole toolpath & $7.932 \mathrm{~s}$ & $6.732 \mathrm{~s}$ \\
\hline \multirow[t]{7}{*}{ Total length } & at constant speed in the OR & $175.442 \mathrm{~mm}$ & $185.470 \mathrm{~mm}$ \\
\hline & of acceleration in the OR & $22.528 \mathrm{~mm}$ & $14.492 \mathrm{~mm}$ \\
\hline & of deceleration in the OR & $17.900 \mathrm{~mm}$ & $14.975 \mathrm{~mm}$ \\
\hline & with $\operatorname{arc} O F F$ inside the OR & $0.205 \mathrm{~mm}$ & N/A \\
\hline & inside the OR & $216.075 \mathrm{~mm}$ & $214.937 \mathrm{~mm}$ \\
\hline & outside the OR & $19.474 \mathrm{~mm}$ & $34.920 \mathrm{~mm}$ \\
\hline & of the whole toolpath & $235.549 \mathrm{~mm}$ & $249.857 \mathrm{~mm}$ \\
\hline \multicolumn{2}{|c|}{ Total "programmed" length } & $261.301 \mathrm{~mm}$ & $261.301 \mathrm{~mm}$ \\
\hline \multicolumn{2}{|c|}{ Total volume of material deposited } & $619.788 \mathrm{~mm}^{3}$ & $634.489 \mathrm{~mm}^{3}$ \\
\hline
\end{tabular}

\subsection{Comparison between the two nominal speeds and the two OR areas}

Table 4 compares the results between the two nominal speeds $(10 \mathrm{~mm} / \mathrm{s}$ and $40 \mathrm{~mm} / \mathrm{s})$ and between the two OR areas $\left(21.5 \times 43 \mathrm{~mm}^{2}\right.$ and $\left.43 \times 86 \mathrm{~mm}^{2}\right)$. The comparison concerns the $45^{\circ}$ triangular strategy with arc $O N$ activated over the whole trajectory. Some comments can be advanced about the ratios of results between the two nominal speeds and between the two areas:

- At a nominal speed of $10 \mathrm{~mm} / \mathrm{s}$, the ratio of total times is equal to 3.68 between the two sizes of OR. It is equal to 3.70 for the total length. Thus, the robot took 3.68 times longer to cover a 3.70 times longer toolpath, which shows a nearly linear response. However, at a nominal speed of $40 \mathrm{~mm} / \mathrm{s}$, the robot took 3.61 times longer to cover a 3.76 times longer toolpath, highlighting a loss of proportionality.

- Concerning this difference ratio of 0.25 between the two nominal speeds, it can be noted that proportionality is clearly respected: the measured time ratio is of 0.26 and 0.25 for small and large OR respectively. When multiplying the nominal speed by four, the travel 
length is lower: a decrease of $3 \%$ and $2 \%$ for the small and large OR respectively, which is not negligible.

Table 4. Comparison between two OR areas and two nominal speeds for the $45^{\circ}$ triangular strategy with $\operatorname{arc} O N$ activated over the whole toolpath

\begin{tabular}{|c|c|c|c|c|c|}
\hline & & 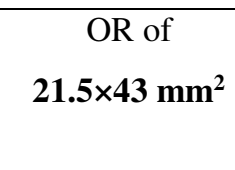 & 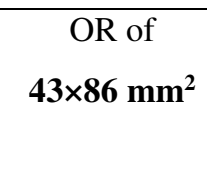 & $\begin{array}{l}\text { Time ratio } \\
\text { between the } \\
\text { two sizes }\end{array}$ & $\begin{array}{l}\text { Length ratio } \\
\text { between the } \\
\text { two sizes }\end{array}$ \\
\hline \multirow[t]{2}{*}{$10 \mathrm{~mm} / \mathrm{s}$} & Time & $26.280 \mathrm{~s}$ & $96.624 \mathrm{~s}$ & 3.68 & \\
\hline & Length & $258.896 \mathrm{~mm}$ & $958.865 \mathrm{~mm}$ & & 3.70 \\
\hline \multirow[t]{2}{*}{$40 \mathrm{~mm} / \mathrm{s}$} & Time & $6.732 \mathrm{~s}$ & $24.300 \mathrm{~s}$ & 3.61 & \\
\hline & Length & $249.857 \mathrm{~mm}$ & $938.206 \mathrm{~mm}$ & & 3.76 \\
\hline \multicolumn{2}{|c|}{ Time ratio between the two speeds } & 0.26 & 0.25 & & \\
\hline \multicolumn{2}{|c|}{ Length ratio between the two speeds } & 0.97 & 0.98 & & \\
\hline
\end{tabular}

Before proposing a manufacturing time model in Section 5, Table A3 in the Appendix provides the results for all the strategies considered in this study, for completeness.

\subsection{Additional experiments}

Finally, experiments were duplicated at 15 various locations in the work space (see schematic view in Fig. 8). Indeed, a serial robot features a priori variable structural stiffness within its workspace [31], and the magnitudes of trajectory errors may vary inside that workspace. The results described in the previous sections corresponded to location " $A$ ". Let us mention that the robot is not placed symmetrically with respect to the work space, justifying the choice of testing symmetrical locations in the chamber. At each location, a trajectory was performed using the swiping strategy and a nominal speed of $20 \mathrm{~mm} / \mathrm{min}$. As in the previous sections, two OR areas were considered: $21.5 \times 43 \mathrm{~mm}^{2}$ and $43 \times 86 \mathrm{~mm}^{2}$. For the small OR, the deposition time varied between $23.840 \mathrm{~s}$ and $23.890 \mathrm{~s}$ depending on the location in the work space. For the large one, it varied between $92.964 \mathrm{~s}$ and $92.988 \mathrm{~s}$. In conclusion, deposition times can be considered as homogeneous within the work space. The same conclusion can be made from the values of the lengths: there is no significant variation between the locations. These results are positive, as they do not reveal any heterogeneity in the workspace of the robot. 


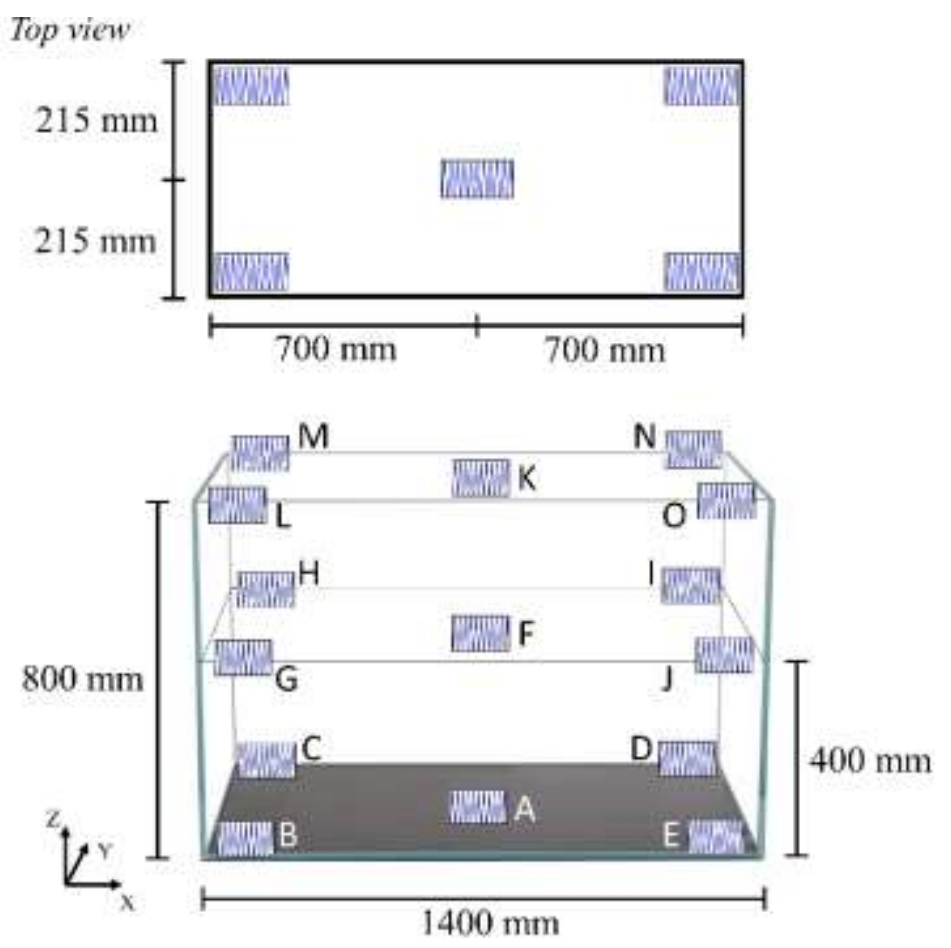

Fig. 8 Schematic view of the inert chamber with the locations of the different zones in which the same swiping depositions were performed

\subsection{General comments}

After presenting and analyzing the results of the experimental tests, some general comments highlight the fact that compromises have to be found between various aspects. From the preliminary study in Section 3.1 (linear trajectory at constant nominal speed), arc ON/OFF switching has two drawbacks which may induce material defects: a "backlash" (due to clearance within the joints of the robots) and a robot stop (accompanied by deceleration/acceleration phases). For these reasons, in the context of the WAAM process, the use of discontinuous deposition should be a priori avoided for quality purposes. From the preliminary study in Section 3.2 (impact of a sharp change in direction), it appears that the robot fails to maintain a constant speed as expected in CVEL mode, leading to an error in both speed and position. The sharper the angle, the slower the robot movement in the transition zones, and the higher the trajectory error. As a general remark, sharp angles should be avoided. In Section 4.2, the toolpath with arc $O N$ over the whole trajectory was more accurate (see Table 4). This may appear contradictory with the previous comments because no robot stops occur when leaving/entering the OR. In fact, the delays (caused by the stops when leaving/entering the OR) when using arc OFF outside the OR appeared to be corrected by the controller by cutting the 
trajectory in the curves (see Fig. 7-a-1), leading to a large trajectory error. However, this is not a priori a problem because this cutting occurs outside the OR.

Various remarks can be made about the comparison between the eight strategies in Section 4.1:

- The advantage of the raster-pass strategy is the high accuracy of the toolpath, because all the deposition sections are along straight lines with robot stops at each ends (due to the switching between $\operatorname{arc} O N$ and $\operatorname{arc} O F F$ ). However, from the production point of view, the raster-pass strategy is not efficient. A large part of the time is non-productive, consuming resources (energy, time, others).

- The semi-circular strategy presents the lowest error between programmed total length and measured total length. This toolpath is also the one with the highest average speed. These two characteristics have a direct positive impact on the quality of the deposition.

- The swiping strategy has the lowest ratio between actual and programmed lengths. This means that the robot does not perform the programmed toolpath completely.

Discontinuous deposition would be relevant when adding extra lengths outside the "nominal" OR, leading in practice to a larger deposition zone. These extra lengths should correspond to acceleration and deceleration phases measured on straight trajectory sections. For instance, for a nominal speed of $40 \mathrm{~mm} / \mathrm{s}$ and the $45^{\circ}$ triangular strategy with $\operatorname{arc} O F F$ outside the OR, these distances can be estimated at $4.5 \mathrm{~mm}$ for the acceleration phases (just before entering the nominal OR) and $3.6 \mathrm{~mm}$ for the deceleration phases (just after leaving the nominal OR). By construction, these values are smaller when $\operatorname{arc} O N$ is activated over the whole trajectory.

The data collected from the swiping experiments at different locations revealed that there is repeatability with respect to the deposition times and total deposition lengths (see Section 4.4). It is therefore possible to apply formulas to calculate the deposition time independently of the location within the work space. 


\section{Time estimation model}

Based on the results of the experiments, a manufacturing time estimation model is now proposed to calculate the manufacturing time of any $W \times L$ area of OR from a limited number of previously-identified parameters for a single area. The method is illustrated for the $45^{\circ}$ triangular strategy, but the principle is the same for the other strategies. Based on the results of the experiments at $10 \mathrm{~mm} / \mathrm{s}$ and $40 \mathrm{~mm} / \mathrm{s}$, Table 5 provides the parameters initially identified for the small OR $\left(21.5 \times 43 \mathrm{~mm}^{2}\right)$, distinguishing whether $O F F$ arc is applied outside the OR or not.

- $T_{\text {init accel }}$ and $L_{\text {init accel }}$ are the time and the length, respectively, of the initial acceleration;

- $\quad L_{\text {accel }}$ and $L_{\text {decel }}$ are the lengths of acceleration and deceleration (respectively) at the beginning and end (respectively) of a horizontal straight section of the toolpath excluding the first and last ones. It can be noted in Table 5 that some values are equal to zero, meaning that acceleration or deceleration phases do not occur in the horizontal straight sections (they are in transitions in between);

- $T_{\text {trans }}$ : time of the transition between two successive horizontal sections of toolpath;

- $T_{\text {final decel }}$ and $L_{\text {final decel }}$ are the time and the length, respectively, of the final deceleration.

Let us note that parameters $T_{\text {init accel }}, L_{\text {init accel }}, T_{\text {final decel }}$ and $L_{\text {final decel }}$ were measured from the median of several experiments with different strategies (they are not specific to the $45^{\circ}$ triangular strategy). On the contrary, as $L_{\text {accel }}, L_{\text {decel }}$ and $T_{\text {trans }}$ are specific to the strategy considered, we measured them for the $45^{\circ}$ triangular strategy (one experiment).

The following formula can then be used to calculate the total time as a function of the $W \times L$ area of the OR, the nominal speed (TS) and the number of horizontal weld beads $n_{\mathrm{WB}}$ calculated from Eqs (1) and (2):

$$
\begin{gathered}
T_{\text {total }}\left(W, L, T S, n_{\mathrm{WB}}\right)=T_{\text {init accel }}(T S)+T_{\text {init const }}(L, T S)+\left(n_{\mathrm{WB}}-1\right) \times T_{\text {trans }}(T S) \\
+\left(n_{\mathrm{WB}}-2\right) \times T_{\text {straight const }}(L, T S)+T_{\text {final const }}(L, T S)+T_{\text {final decel }}(T S)
\end{gathered}
$$

where: 
- $T_{\text {init const }}$ is the duration of the first horizontal straight section at constant speed:

$$
T_{\text {init const }}=\frac{L-L_{\text {init accel }}(T S)-L_{\text {decel }}(T S)}{T S}
$$

- $T_{\text {straight const }}$ is the duration of any horizontal straight section at constant speed, excluding the first and final ones:

$$
T_{\text {straight const }}=\frac{L-L_{\text {accel }}(T S)-L_{\text {decel }}(T S)}{T S}
$$

- $T_{\text {final_const }}$ is the duration of the final horizontal straight section at constant speed:

$$
T_{\text {final const }}=\frac{L-L_{\text {accel }}(T S)-L_{\text {final decel }}(T S)}{T S}
$$

As an evaluation of the accuracy of the formula, numerical applications were performed to calculate the total times for the large $\mathrm{OR}(W=43 \mathrm{~mm}$ and $L=86 \mathrm{~mm})$ from the parameters identified for the small OR. They give:

- for $T S=10 \mathrm{~mm} / \mathrm{s}$ and $\operatorname{arc} O N$ over the whole trajectory: $96.982 \mathrm{~s}$, i.e. $0.38 \%$ of error with respect with measured value (96.612 s, see Table A2 in Appendix);

- for $T S=10 \mathrm{~mm} / \mathrm{s}$ and $\operatorname{arc} O F F$ outside the OR: $98.081 \mathrm{~s}$, i.e. $2.28 \%$ of error with respect with measured value (100.368 s);

- for $T S=40 \mathrm{~mm} / \mathrm{s}$ and $\operatorname{arc} O N$ over the whole trajectory: 24.304 s, i.e. $0.03 \%$ of error with respect with measured value (24.312 s);

- for $T S=40 \mathrm{~mm} / \mathrm{s}$ and $\operatorname{arc} O F F$ outside the OR: $23.544 \mathrm{~s}$, i.e. $16.3 \%$ of error with respect with measured value $(28.128 \mathrm{~s})$.

The same approach was adopted to calculate the total times for the small OR from the parameters identified for the large OR. This gives $0.24 \%, 3.5 \%, 0.33 \%$ and $9.3 \%$ of error respectively (calculation not reported here). Thus we consider that the formula is precise for all the cases with arc ON activated over the whole trajectory: the errors are less than $0.4 \%$. The error is higher with arc OFF activated outside the OR: up to $16.3 \%$. This is mainly due to the assessment of $L_{\text {accel }}, L_{\text {decel }}$ and $T_{\text {trans }}$ which was performed from one experiment, as noted above. This highlights the importance of the preliminary assessment of these parameters when using the manufacturing time model. 


\section{Conclusion}

In the WAAM process, the accuracy of the toolpath is of prime importance for the mechanical properties of the final part because of the material defects that could be generated. This accuracy depends on the kinematic behavior of the robot, as well as the interaction between CMT equipment and robot controllers. Beyond the cases treated in this paper and the chosen test conditions (speeds, dimensions...), this type of study shows that a kinematic analysis of the robot's behavior brings valuable information for off-line trajectory programming. It is possible to build rules that can be used by the manufacturer to correctly program the trajectory before building a part.

A motion analysis of the nozzle using a KUKA KR 100-2 HA 2000 robot with a KRC2 controller was performed in this study. The movement of the nozzle was analyzed without depositing material (trajectory definition only) using various strategies, nozzle speeds and layer areas for continuous and discontinuous "virtual" depositions. The analysis also enabled us to identify various problems associated with acceleration and deceleration phases, in particular for discontinuous depositions. Several points can be highlighted:

- Discontinuous deposition leads to additional travel time, due to deceleration and acceleration at each deposition stop and restart respectively. However, it has the advantage of saving material (in sections intended to be transient).

- Planning sections of the toolpath outside the nominal deposition area can be useful to "move" inaccuracy problems to where they are not critical from a material quality perspective. Discontinuous deposition would be relevant when adding extra lengths outside the nominal deposition area, leading in practice to a larger deposition zone. These extra lengths should correspond to acceleration and deceleration phases measured on straight trajectory sections. Deposition outside the nominal deposition area may also be relevant, but it requires additional conventional machining time and tooling.

- The swiping strategy is the most commonly-used but it has limits and is not applicable to all cases. It can be useful to have other strategies, as proposed in this paper. Sharp changes in direction in the programmed toolpath actually lead to a trajectory error. Thus the semi-circular strategy (G1 continuous) enables this accuracy problem to be lessened.

- It is possible to define manufacturing time estimation models taking into account acceleration and deceleration phases. However, stopping deposition outside the nominal 
deposition area requires precise parameter identification for a correct calculation of the manufacturing time.

As a general comment from the above points, compromises must therefore be found. Based on the tests performed in this study, the semi-circular strategy appears to be the most relevant in the case of continuous deposition over the whole toolpath. Perspectives of the study include the consideration of cooling in the definition of in-plane and inter-layer trajectories.

\section{References}

1. Dinovitzer M, Chen XH, Laliberte J, Huang X, Frei H, (2019) Effect of wire and arc additive manufacturing (WAAM) process parameters on bead geometry and microstructure. Addit Manuf 26:138-146. https://doi.org/10.1016/j.addma.2018.12.013

2. McAndrew AR, Rosales MA, Colegrove PA, Honnige JR, Ho A, Fayolle R, Eyitayo K, Stan I, Sukrongpang P, Crochemore A, Pinter Z (2018) Interpass rolling of Ti-6Al-4V wire + arc additively manufactured features for microstructural refinement. Addit Manuf 21:340-349. https://doi.org/10.1016/j.addma.2018.03.006

3. Williams SW, Martina F, Addison AC, Ding J, Pardal G, Colegrove P (2016) Wire plus Arc Additive Manufacturing. Mater Sci Technol 32:641-647. https://doi.org/10.1179/1743284715Y.0000000073

4. Ding DH, Pan ZX, Cuiuri D, Li HJ (2015) Process planning for robotic wire and arc additive manufacturing, In: IEEE (ed) Proceedings of the 2015 10th IEEE Conference on Industrial Electronics and Applications. IEEE Conference on Industrial Electronics and Applications. IEEE, New York, pp 1994-1997. https://doi.org/10.1109/ICIEA.2015.7334441

5. Fuchs C, Baier D, Semm T, Zaeh MF (2020) Determining the machining allowance for WAAM parts. Prod Eng Res Devel 14:629-637. https://doi.org/10.1007/s11740-02000982-9

6. Almeida PMS, Williams S (2010) Innovative process model of Ti-6Al-4V additive layer manufacturing using cold metal transfer (CMT). In: 21st Annual International Solid Freeform Fabrication Symposium: An Additive Manufacturing Conference. 9-11 August 2010, Austin, Texas, USA. University of Texas. https://doi.org/10.26153/tsw/15162

7. Li JH, Zhou XL, Meng QB, Brochu M, Chekir N, Sixsmith JJ, Hascoet JY, Zhao ZF (2021) Deterministic modeling of solidification microstructure formation in directed energy 
deposition fabricated Ti6Al4V. Addit Manuf 46:102182.

https://doi.org/10.1016/j.addma.2021.102182

8. Evjemo LD, Moe S, Gravdahl JT (2020) Robotised wire arc additive manufacturing using set-based control: experimental results. In: IFAC-PapersOnLine, vol. 53(2), pp. 10044-10051. 21st IFAC World Congress on Automatic Control - Meeting Societal Challenges, Elsevier, Amsterdam, Netherland. https://doi.org/10.1016/j.ifacol.2020.12.2725

9. Jafari D, Vaneker THJ, Gibson I (2021) Wire and arc additive manufacturing: opportunities and challenges to control the quality and accuracy of manufactured parts. Mater Des 202:109471. https://doi.org/10.1016/j.matdes.2021.109471

10. Ferreira RP, Scotti A (2021) The concept of a novel path planning strategy for wire plus arc additive manufacturing of bulky parts: pixel. Metals 11:498. https://doi.org/10.3390/met11030498

11. Michel F, Lockett H, Ding J, Martina F, Marinelli G, Williams S (2019) A modular path planning solution for Wire + Arc Additive Manufacturing. Robot Comput-Integr Manuf 60:1-11. https://doi.org/10.1016/j.rcim.2019.05.009

12. Thompson B, Yoon HS (2014) Efficient path planning algorithm for additive manufacturing systems. IEEE Trans Compon Packag Manuf Technol 4:1555-1563. https://doi.org/10.1109/TCPMT.2014.2338791

13. Chokkalingham S, Chandrasekhar N, Vasudevan M (2012) Predicting the depth of penetration and weld bead width from the infra red thermal image of the weld pool using artificial neural network modeling. J Intell Manuf 23:1995-2001.

https://doi.org/10.1007/s10845-011-0526-4

14. Cunningham CR, Flynn JM, Shokrani A, Dhokia V, Newman ST (2018) Invited review article: Strategies and processes for high quality wire arc additive manufacturing. Addit Manuf 22:672-686. https://doi.org/10.1016/j.addma.2018.06.020

15. Bertoldi M, Yardimci MA, Pistor CM, Guceri SI (1998) Domain decomposition and space filling curves in toolpath planning and generation. In: Marcus HL, Beaman JJ, Bourell DL, Barlow JW, Crawford RH (eds) Solid Freeform Fabrication Proceedings, August 1998, Solid Freeform Fabrication Proceedings (Series). Univ Texas Austin, Austin, RX, USA, pp 267-274. https://doi.org/10.26153/tsw/608

16. Yang Y, Loh HT, Fuh JYH, Wang YG (2002) Equidistant path generation for improving scanning efficiency in layered manufacturing. Rapid Prototyp J 8:30-37. https://doi.org/10.1108/13552540210413284 
17. Zhang YM, Chen YW, Li PJ, Male AT (2003) Weld deposition-based rapid prototyping: a preliminary study. J Mater Process Technol 135:347-357. https://doi.org/10.1016/S09240136(02)00867-1

18. Ding DH, Pan ZX, Cuiuri D, Li HJ (2015) A practical path planning methodology for wire and arc additive manufacturing of thin-walled structures. Robot Comput-Integr Manuf 34:8-19. https://doi.org/10.1016/j.rcim.2015.01.003

19. Aldalur E, Veiga F, Suárez A, Bilbao J, Lamikiz A (2020) High deposition wire arc additive manufacturing of mild steel: Strategies and heat input effect on microstructure and mechanical properties. J Manuf Process 58:615-626. https://doi.org/10.1016/j.jmapro.2020.08.060

20. Yang Y, Loh HT, Fuh JYH, Wang YG (2002) Equidistant path generation for improving scanning efficiency in layered manufacturing. Rapid Prototyp J 8:30-37. https://doi.org/10.1108/13552540210413284

21. Liu XM, Qiu CR, Zeng QF, Li AP (2019) Kinematics analysis and trajectory planning of collaborative welding robot with multiple manipulators, In: P. Butala, E. Goverak, R. Vrabic (eds) 52nd CIRP Conference on Manufacturing Systems (CMS), Procedia CIRP, vol. 81. Elsevier, Amsterdam, Netherland, pp 1034-1039.

https://doi.org/10.1016/j.procir.2019.03.247

22. Jin GQ, Li WD, Gao L (2013) An adaptive process planning approach of rapid prototyping and manufacturing. Robot Comput-Integr Manuf 29:23-38. https://doi.org/10.1016/j.rcim.2012.07.001

23. Rauch M, Nwankpa UV, Hascoet JY (2021) Investigation of deposition strategy on wire and arc additive manufacturing of aluminium components. J Adv Joining Process 4:100074. https://doi.org/10.1016/j.jajp.2021.100074

24. Ding DH, Pan ZX, Cuiuri D, Li HJ (2014) A tool-path generation strategy for wire and arc additive manufacturing. Int J Adv Manuf Technol 73:173-183. https://doi.org/10.1007/s00170-014-5808-5

25. Diourté A, Bugarin F, Bordreuil C, Segonds S (2021) Continuous three-dimensional path planning (CTPP) for complex thin parts with wire arc additive manufacturing. Addit Manuf 37:101622. https://doi.org/10.1016/j.addma.2020.101622

26. Li F, Chen SJ, Shi JB, Zhao Y, Tian HY (2018) Thermoelectric cooling-aided bead geometry regulation in wire and arc-based additive manufacturing of thin-walled structures. Appl Sci Basel 8:207. https://doi.org/10.3390/app8020207 
27. Geng HB, Li JL, Xiong JT, Lin X (2017) Optimisation of interpass temperature and heat input for wire and arc additive manufacturing 5A06 aluminium alloy. Sci Technol Weld Joining 22:472-483. https://doi.org/10.1080/13621718.2016.1259031.

28. Zhao Y, Jia YZ, Chen SJ, Shi JB, Li F (2020) Process planning strategy for wire-arc additive manufacturing: thermal behavior considerations. Addit Manuf 32:100935. https://doi.org/10.1016/j.addma.2019.100935

29. KUKA.RobotSensorInterface 3.1 - For KUKA System Software 8.2, Issued: 23.12.2010, Version: KST RSI 3.1 V1 en. KUKA Roboter GmbH, Augsburg, Germany, 2010. http://supportwop.com/IntegrationRobot/content/6Syst\%C3\%A8mes_int\%C3\%A9grations/RobotSensorInterface/KST_RSI_31_en.pdf. Accessed 09 January 2022

30. Nguyen L, Buhl J, Bambach M (2020) Continuous Eulerian toolpath strategies for wirearc additive manufacturing of rib-web structures with machine-learning-based adaptive void filling. Addit Manuf 35:101265. https://doi.org/10.1016/j.addma.2020.101265

31. Sun JB, Zhang WM, Liu ZH (2018) Translation Stiffness Calculation for Serial Robots. In: ICRAI 2018: Proceedings of 2018 4th International Conference on Robotics and Artificial Intelligence. Assoc Computing Machinary, New York, USA, pp 87-91. https://doi.org/10.1145/3297097.3297103

\section{Statements and Declarations}

Funding This work was supported by the French Research Agency through the Indus Addi project ( ${ }^{\circ}$ ANR-19-CE10-0001-01).

Competing Interests The authors declare no competing of interest.

Data Availability The datasets generated during and/or analyzed during the current study are available from the corresponding author on reasonable request.

Author contribution R. Viola Da Silva: Conceptualization, Methodology, Validation, Formal analysis, Software, Investigation, Data curation, Writing - original draft, Writing - review \& editing, Visualization. X. Balandraud: Conceptualization, Methodology, Validation, Formal analysis, Writing - review \& editing, Visualization, Supervision. F. Poulhaon: Conceptualization, Methodology, Validation, Formal analysis, Resources, Writing - review \& editing, Supervision. P. Michaud: Conceptualization, Methodology, Formal analysis, Resources, Writing - review \& editing, Project administration. E. Duc: Conceptualization, 
Methodology, Formal analysis, Resources, Writing - review \& editing, Project administration, Funding acquisition.

\section{Compliance with ethical standards N/A}


Table A1 (Appendix). Comparison between different strategies and two nominal speeds for the small OR $\left(21.5 \times 43 \mathrm{~mm}^{2}\right)$. Measured parameters are the total time and length over the whole toolpath, as well as the total volume of material deposited (i.e. when $\operatorname{arc} O N$ is activated).

\begin{tabular}{|c|c|c|c|c|c|}
\hline \multirow[t]{2}{*}{ Strategy } & \multirow{2}{*}{$\begin{array}{l}\text { Nominal } \\
\text { speed }\end{array}$} & \multirow{2}{*}{$\begin{array}{l}\text { Measured } \\
\text { parameter }\end{array}$} & \multirow{2}{*}{$\begin{array}{l}\text { With } \operatorname{arc} O N \text { over } \\
\text { the whole toolpath }\end{array}$} & \multicolumn{2}{|c|}{ With $\operatorname{arc} O F F$ outside the OR } \\
\hline & & & & $\begin{array}{l}\text { Over the whole } \\
\text { toolpath }\end{array}$ & When $\operatorname{arc}$ is $O N$ \\
\hline \multirow[t]{6}{*}{ Raster-pass } & $10 \mathrm{~mm} / \mathrm{s}$ & Time & N/A & $40.644 \mathrm{~s}$ & $22.38 \mathrm{~s}$ \\
\hline & & Length & N/A & $387.900 \mathrm{~mm}$ & $215.084 \mathrm{~mm}$ \\
\hline & & Volume & N/A & $2118.353 \mathrm{~mm}^{3}$ & $2108.176 \mathrm{~mm}^{3}$ \\
\hline & $40 \mathrm{~mm} / \mathrm{s}$ & Time & N/A & $11.580 \mathrm{~s}$ & $6.408 \mathrm{~s}$ \\
\hline & & Length & N/A & $386.971 \mathrm{~mm}$ & $214.712 \mathrm{~mm}$ \\
\hline & & Volume & N/A & $615.133 \mathrm{~mm}^{3}$ & $605.083 \mathrm{~mm}^{3}$ \\
\hline Triangular & $10 \mathrm{~mm} / \mathrm{s}$ & Time & $26.280 \mathrm{~s}$ & $27.972 \mathrm{~s}$ & $22.152 \mathrm{~s}$ \\
\hline \multirow[t]{5}{*}{$45^{\circ}$} & & Length & $258.896 \mathrm{~mm}$ & $259.877 \mathrm{~mm}$ & $215.642 \mathrm{~mm}$ \\
\hline & & Volume & $2476.881 \mathrm{~mm}^{3}$ & $2159.070 \mathrm{~mm}^{3}$ & $2085.557 \mathrm{~mm}^{3}$ \\
\hline & $40 \mathrm{~mm} / \mathrm{s}$ & Time & $6.732 \mathrm{~s}$ & $7.932 \mathrm{~s}$ & $6.132 \mathrm{~s}$ \\
\hline & & Length & $249.857 \mathrm{~mm}$ & $235.549 \mathrm{~mm}$ & $215.870 \mathrm{~mm}$ \\
\hline & & Volume & $634.489 \mathrm{~mm}^{3}$ & $619.788 \mathrm{~mm}^{3}$ & $577.939 \mathrm{~mm}^{3}$ \\
\hline Triangular & $10 \mathrm{~mm} / \mathrm{s}$ & Time & $25.212 \mathrm{~s}$ & $26.856 \mathrm{~s}$ & $22.152 \mathrm{~s}$ \\
\hline \multirow[t]{5}{*}{$60^{\circ}$} & & Length & $248.426 \mathrm{~mm}$ & $249.427 \mathrm{~mm}$ & $215.889 \mathrm{~mm}$ \\
\hline & & Volume & $2376.223 \mathrm{~mm}^{3}$ & $2165.724 \mathrm{~mm}^{3}$ & $2085.557 \mathrm{~mm}^{3}$ \\
\hline & $40 \mathrm{~mm} / \mathrm{s}$ & Time & $6.456 \mathrm{~s}$ & $8.172 \mathrm{~s}$ & $6.096 \mathrm{~s}$ \\
\hline & & Length & $240.050 \mathrm{~mm}$ & $242.118 \mathrm{~mm}$ & $215.360 \mathrm{~mm}$ \\
\hline & & Volume & $608.476 \mathrm{~mm}^{3}$ & $615.264 \mathrm{~mm}^{3}$ & $574.546 \mathrm{~mm}^{3}$ \\
\hline Triangular & $10 \mathrm{~mm} / \mathrm{s}$ & Time & $24.156 \mathrm{~s}$ & $25.848 \mathrm{~s}$ & $22.068 \mathrm{~s}$ \\
\hline \multirow[t]{5}{*}{$90^{\circ}$} & & Length & $238.759 \mathrm{~mm}$ & $239.893 \mathrm{~mm}$ & $215.354 \mathrm{~mm}$ \\
\hline & & Volume & $2276.695 \mathrm{~mm}^{3}$ & $2161.332 \mathrm{~mm}^{3}$ & $2082.164 \mathrm{~mm}^{3}$ \\
\hline & $40 \mathrm{~mm} / \mathrm{s}$ & Time & $6.180 \mathrm{~s}$ & $7.932 \mathrm{~s}$ & $6.132 \mathrm{~s}$ \\
\hline & & Length & $230.613 \mathrm{~mm}$ & $235.549 \mathrm{~mm}$ & $215.870 \mathrm{~mm}$ \\
\hline & & Volume & $582.463 \mathrm{~mm}^{3}$ & $613.002 \mathrm{~mm}^{3}$ & $577.939 \mathrm{~mm}^{3}$ \\
\hline \multirow[t]{6}{*}{ Rectangular } & $10 \mathrm{~mm} / \mathrm{s}$ & Time & $21.936 \mathrm{~s}$ & N/A & N/A \\
\hline & & Length & $215.997 \mathrm{~mm}$ & N/A & N/A \\
\hline & & Volume & $2067.461 \mathrm{~mm}^{3}$ & N/A & N/A \\
\hline & $40 \mathrm{~mm} / \mathrm{s}$ & Time & $5.664 \mathrm{~s}$ & N/A & N/A \\
\hline & & Length & $207.618 \mathrm{~mm}$ & N/A & N/A \\
\hline & & Volume & $533.830 \mathrm{~mm}^{3}$ & N/A & N/A \\
\hline \multirow[t]{2}{*}{ Semi-circular } & $10 \mathrm{~mm} / \mathrm{s}$ & Time & $24.384 \mathrm{~s}$ & $26.136 \mathrm{~s}$ & $21.840 \mathrm{~s}$ \\
\hline & & Length & $242.306 \mathrm{~mm}$ & $243.187 \mathrm{~mm}$ & $212.385 \mathrm{~mm}$ \\
\hline
\end{tabular}




\begin{tabular}{|c|c|c|c|c|c|}
\hline & & Volume & $2298.184 \mathrm{~mm}^{3}$ & $2110.440 \mathrm{~mm}^{3}$ & $2057.282 \mathrm{~mm}^{3}$ \\
\hline & \multirow[t]{3}{*}{$40 \mathrm{~mm} / \mathrm{s}$} & Time & $6.264 \mathrm{~s}$ & $7.908 \mathrm{~s}$ & $6.108 \mathrm{~s}$ \\
\hline & & Length & $234.201 \mathrm{~mm}$ & $237.967 \mathrm{~mm}$ & $212.722 \mathrm{~mm}$ \\
\hline & & Volume & $590.380 \mathrm{~mm}^{3}$ & $607.347 \mathrm{~mm}^{3}$ & $576.808 \mathrm{~mm}^{3}$ \\
\hline \multirow[t]{6}{*}{ Spiral } & \multirow[t]{3}{*}{$10 \mathrm{~mm} / \mathrm{s}$} & Time & $21.720 \mathrm{~s}$ & N/A & N/A \\
\hline & & Length & $214.383 \mathrm{~mm}$ & N/A & N/A \\
\hline & & Volume & $2047.103 \mathrm{~mm}^{3}$ & N/A & N/A \\
\hline & \multirow[t]{3}{*}{$40 \mathrm{~mm} / \mathrm{s}$} & Time & $5.628 \mathrm{~s}$ & N/A & N/A \\
\hline & & Length & $206.322 \mathrm{~mm}$ & N/A & N/A \\
\hline & & Volume & $530.437 \mathrm{~mm}^{3}$ & N/A & N/A \\
\hline \multirow[t]{6}{*}{ Swiping } & \multirow[t]{3}{*}{$10 \mathrm{~mm} / \mathrm{s}$} & Time & $47.604 \mathrm{~s}$ & N/A & N/A \\
\hline & & Length & $459.242 \mathrm{~mm}$ & N/A & N/A \\
\hline & & Volume & $4486.661 \mathrm{~mm}^{3}$ & N/A & N/A \\
\hline & \multirow[t]{3}{*}{$40 \mathrm{~mm} / \mathrm{s}$} & Time & $12.036 \mathrm{~s}$ & N/A & N/A \\
\hline & & Length & $411.509 \mathrm{~mm}$ & N/A & N/A \\
\hline & & Volume & $1134.389 \mathrm{~mm}^{3}$ & N/A & N/A \\
\hline
\end{tabular}


Table A2 (Appendix). Same as Table A1, but for the large OR $\left(43 \times 86 \mathrm{~mm}^{2}\right)$.

\begin{tabular}{|c|c|c|c|c|c|}
\hline \multirow[t]{2}{*}{ Strategy } & \multirow{2}{*}{$\begin{array}{l}\text { Nominal } \\
\text { speed }\end{array}$} & \multirow{2}{*}{$\begin{array}{l}\text { Measured } \\
\text { parameter }\end{array}$} & \multirow{2}{*}{$\begin{array}{l}\text { With } \operatorname{arc} O N \text { over the } \\
\text { whole toolpath }\end{array}$} & \multicolumn{2}{|c|}{ With $\operatorname{arc} O F F$ outside the OR } \\
\hline & & & & $\begin{array}{l}\text { Over the whole } \\
\text { toolpath }\end{array}$ & $\begin{array}{l}\text { When } \operatorname{arc} \text { is } \\
\text { ON }\end{array}$ \\
\hline \multirow[t]{6}{*}{ Raster-pass } & $10 \mathrm{~mm} / \mathrm{s}$ & Time & N/A & $167.436 \mathrm{~s}$ & $87.708 \mathrm{~s}$ \\
\hline & & Length & N/A & $1636.161 \mathrm{~mm}$ & $860.635 \mathrm{~mm}$ \\
\hline & & Volume & N/A & $8270.973 \mathrm{~mm}^{3}$ & $8265.319 \mathrm{~mm}^{3}$ \\
\hline & $40 \mathrm{~mm} / \mathrm{s}$ & Time & N/A & $44.880 \mathrm{~s}$ & $23.436 \mathrm{~s}$ \\
\hline & & Length & N/A & $1634.200 \mathrm{~mm}$ & $859 ; 632 \mathrm{~mm}$ \\
\hline & & Volume & N/A & $2220.143 \mathrm{~mm}^{3}$ & $2206.573 \mathrm{~mm}^{3}$ \\
\hline Triangular & $10 \mathrm{~mm} / \mathrm{s}$ & Time & $96.612 \mathrm{~s}$ & $100.368 \mathrm{~s}$ & $87.084 \mathrm{~s}$ \\
\hline \multirow[t]{5}{*}{$45^{\circ}$} & & Length & $959.644 \mathrm{~mm}$ & $961.592 \mathrm{~mm}$ & $861.657 \mathrm{~mm}$ \\
\hline & & Volume & $9105.649 \mathrm{~mm}^{3}$ & $8346.780 \mathrm{~mm}^{3}$ & $8204.245 \mathrm{~mm}^{3}$ \\
\hline & $40 \mathrm{~mm} / \mathrm{s}$ & Time & $24.312 \mathrm{~s}$ & $28.128 \mathrm{~s}$ & $22.812 \mathrm{~s}$ \\
\hline & & Length & $939.284 \mathrm{~mm}$ & $941.410 \mathrm{~mm}$ & $860.906 \mathrm{~mm}$ \\
\hline & & Volume & $2291.398 \mathrm{~mm}^{3}$ & $2220.143 \mathrm{~mm}^{3}$ & $2151.154 \mathrm{~mm}^{3}$ \\
\hline Triangular & $10 \mathrm{~mm} / \mathrm{s}$ & Time & $94.140 \mathrm{~s}$ & $97.932 \mathrm{~s}$ & $87.096 \mathrm{~s}$ \\
\hline \multirow[t]{5}{*}{$60^{\circ}$} & & Length & $936.174 \mathrm{~mm}$ & $938.188 \mathrm{~mm}$ & $861.729 \mathrm{~mm}$ \\
\hline & & Volume & $8872.663 \mathrm{~mm}^{3}$ & $8376.156 \mathrm{~mm}^{3}$ & $8204.245 \mathrm{~mm}^{3}$ \\
\hline & $40 \mathrm{~mm} / \mathrm{s}$ & Time & $23.712 \mathrm{~s}$ & $27.600 \mathrm{~s}$ & $22.824 \mathrm{~s}$ \\
\hline & & Length & $917.451 \mathrm{~mm}$ & $922.234 \mathrm{~mm}$ & $862.392 \mathrm{~mm}$ \\
\hline & & Volume & $2234.848 \mathrm{~mm}^{3}$ & $2226.929 \mathrm{~mm}^{3}$ & $2148.892 \mathrm{~mm}^{3}$ \\
\hline Triangular & $10 \mathrm{~mm} / \mathrm{s}$ & Time & $91.800 \mathrm{~s}$ & $95.616 \mathrm{~s}$ & $87.036 \mathrm{~s}$ \\
\hline \multirow[t]{5}{*}{$90^{\circ}$} & & Length & $914.583 \mathrm{~mm}$ & $916.983 \mathrm{~mm}$ & $861.650 \mathrm{~mm}$ \\
\hline & & Volume & $8652.119 \mathrm{~mm}^{3}$ & $8336.571 \mathrm{~mm}^{3}$ & $8199.721 \mathrm{~mm}^{3}$ \\
\hline & $40 \mathrm{~mm} / \mathrm{s}$ & Time & $23.124 \mathrm{~s}$ & $26.988 \mathrm{~s}$ & $22.956 \mathrm{~s}$ \\
\hline & & Length & $895.988 \mathrm{~mm}$ & $907.158 \mathrm{~mm}$ & $861.719 \mathrm{~mm}$ \\
\hline & & Volume & $2179.429 \mathrm{~mm}^{3}$ & $2226.929 \mathrm{~mm}^{3}$ & $2160.202 \mathrm{~mm}^{3}$ \\
\hline \multirow[t]{6}{*}{ Rectangular } & $10 \mathrm{~mm} / \mathrm{s}$ & Time & $87.360 \mathrm{~s}$ & N/A & N/A \\
\hline & & Length & $869.174 \mathrm{~mm}$ & N/A & N/A \\
\hline & & Volume & $8233.651 \mathrm{~mm}^{3}$ & N/A & N/A \\
\hline & $40 \mathrm{~mm} / \mathrm{s}$ & Time & $21.996 \mathrm{~s}$ & N/A & N/A \\
\hline & & Length & $848.838 \mathrm{~mm}$ & N/A & N/A \\
\hline & & Volume & $2073.116 \mathrm{~mm}^{3}$ & N/A & N/A \\
\hline \multirow[t]{4}{*}{ Semi-circular } & $10 \mathrm{~mm} / \mathrm{s}$ & Time & $92.304 \mathrm{~s}$ & $96.024 \mathrm{~s}$ & $87.228 \mathrm{~s}$ \\
\hline & & Length & $921.243 \mathrm{~mm}$ & $922.426 \mathrm{~mm}$ & $861.216 \mathrm{~mm}$ \\
\hline & & Volume & $8699.621 \mathrm{~mm}^{3}$ & $8277.759 \mathrm{~mm}^{3}$ & $8221.210 \mathrm{~mm}^{3}$ \\
\hline & $40 \mathrm{~mm} / \mathrm{s}$ & Time & $23.232 \mathrm{~s}$ & $27.060 \mathrm{~s}$ & $23.244 \mathrm{~s}$ \\
\hline
\end{tabular}




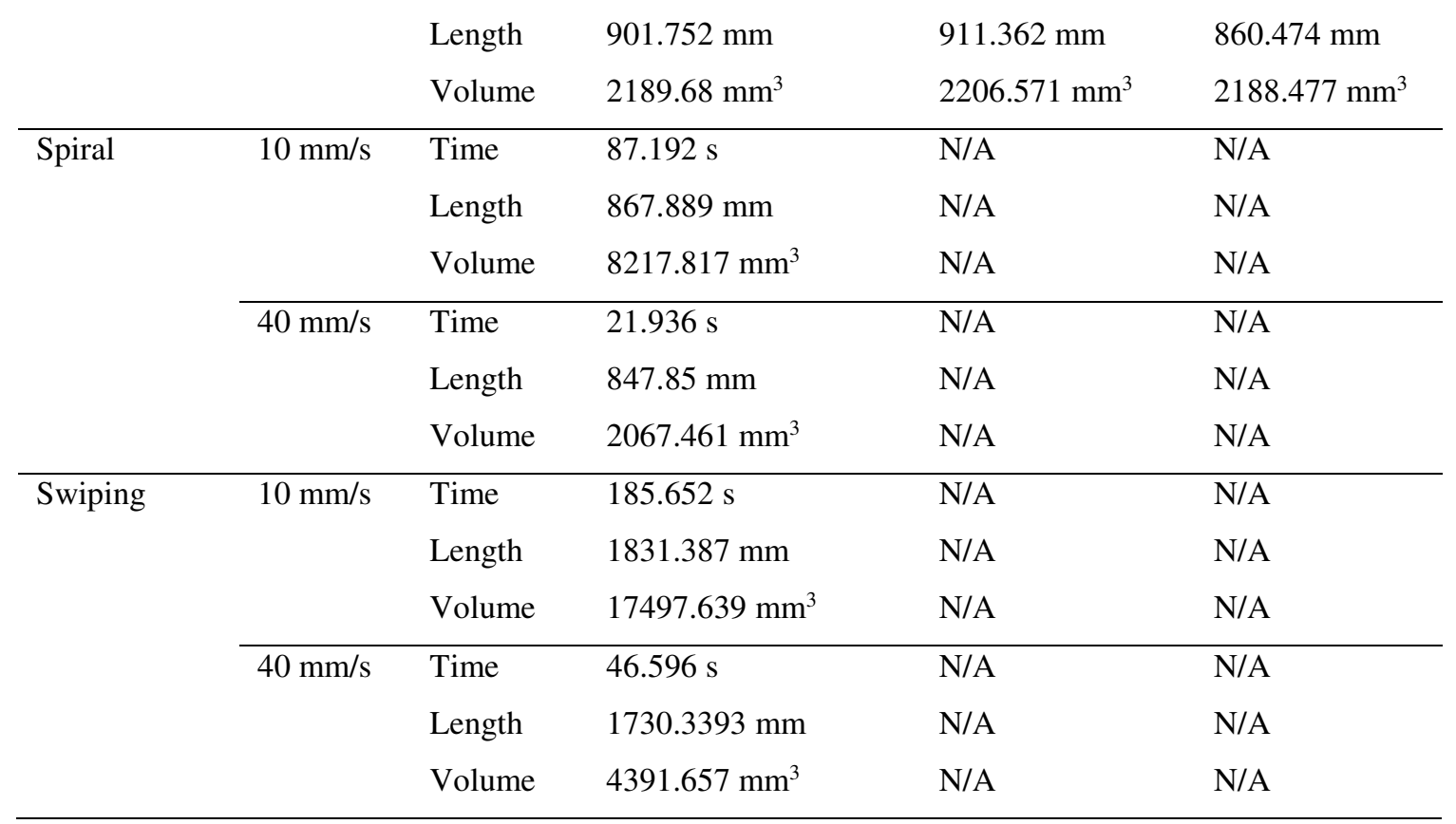


Table A3 (Appendix). Impact of switching between $\operatorname{arc} O N$ and $\operatorname{arc} O F F$ for the four strategies featuring a toolpath outside the OR. Comparison is made for two nominal speeds and two OR areas $\left(21.5 \times 43 \mathrm{~mm}^{2}\right.$ and $43 \times 86 \mathrm{~mm}^{2}$, simply written "small" and "large" respectively in the table).

\begin{tabular}{|c|c|c|c|c|c|}
\hline Strategy & $\begin{array}{c}\text { Nominal } \\
\text { speed }\end{array}$ & OR size & Total time & $\begin{array}{l}\text { With } \operatorname{arc} O F F \\
\text { outside the OR }\end{array}$ & $\begin{array}{l}\text { With } \operatorname{arc} O N \text { over } \\
\text { the whole toolpath }\end{array}$ \\
\hline \multirow{8}{*}{$\begin{array}{l}\text { Semi- } \\
\text { circular }\end{array}$} & \multirow{4}{*}{$10 \mathrm{~mm} / \mathrm{s}$} & \multirow{2}{*}{ Small } & inside the OR & $22.524 \mathrm{~s}$ & $21.552 \mathrm{~s}$ \\
\hline & & & outside the OR & $3.612 \mathrm{~s}$ & $2.832 \mathrm{~s}$ \\
\hline & & \multirow{2}{*}{ Large } & inside the O.R & $87.708 \mathrm{~s}$ & $86.184 \mathrm{~s}$ \\
\hline & & & outside the OR & $8.316 \mathrm{~s}$ & $6.12 \mathrm{~s}$ \\
\hline & \multirow{4}{*}{$40 \mathrm{~mm} / \mathrm{s}$} & \multirow{2}{*}{ Small } & inside the OR & $6.372 \mathrm{~s}$ & $5.628 \mathrm{~s}$ \\
\hline & & & outside the OR & $1.536 \mathrm{~s}$ & $0.636 \mathrm{~s}$ \\
\hline & & \multirow{2}{*}{ Large } & inside the OR & $23.604 \mathrm{~s}$ & $21.852 \mathrm{~s}$ \\
\hline & & & outside the OR & $3.444 \mathrm{~s}$ & $1.380 \mathrm{~s}$ \\
\hline \multirow{8}{*}{$\begin{array}{c}\text { Triangular } \\
45^{\circ}\end{array}$} & \multirow{4}{*}{$10 \mathrm{~mm} / \mathrm{s}$} & \multirow{2}{*}{ Small } & inside the OR & $22.152 \mathrm{~s}$ & $21.660 \mathrm{~s}$ \\
\hline & & & outside the OR & $1.644 \mathrm{~s}$ & $4.620 \mathrm{~s}$ \\
\hline & & \multirow{2}{*}{ Large } & inside the OR & $87.456 \mathrm{~s}$ & $86.160 \mathrm{~s}$ \\
\hline & & & outside the OR & $12.912 \mathrm{~s}$ & $10.452 \mathrm{~s}$ \\
\hline & \multirow{4}{*}{$40 \mathrm{~mm} / \mathrm{s}$} & \multirow{2}{*}{ Small } & inside the OR & $6.288 \mathrm{~s}$ & $5.580 \mathrm{~s}$ \\
\hline & & & outside the OR & $1.644 \mathrm{~s}$ & $1.152 \mathrm{~s}$ \\
\hline & & \multirow{2}{*}{ Large } & inside the OR & $23.172 \mathrm{~s}$ & $21.720 \mathrm{~s}$ \\
\hline & & & outside the OR & $4.956 \mathrm{~s}$ & $2.592 \mathrm{~s}$ \\
\hline \multirow{8}{*}{$\begin{array}{c}\text { Triangular } \\
60^{\circ}\end{array}$} & \multirow{4}{*}{$10 \mathrm{~mm} / \mathrm{s}$} & \multirow{2}{*}{ Small } & inside the OR & $22.152 \mathrm{~s}$ & $21.684 \mathrm{~s}$ \\
\hline & & & outside the OR & $4.524 \mathrm{~s}$ & $3.528 \mathrm{~s}$ \\
\hline & & \multirow{2}{*}{ Large } & inside the OR & $87.468 \mathrm{~s}$ & $86.124 \mathrm{~s}$ \\
\hline & & & outside the OR & $10.308 \mathrm{~s}$ & $8.016 \mathrm{~s}$ \\
\hline & \multirow{4}{*}{$40 \mathrm{~mm} / \mathrm{s}$} & \multirow{2}{*}{ Small } & inside the OR & $6.216 \mathrm{~s}$ & $5.580 \mathrm{~s}$ \\
\hline & & & outside the OR & $1.956 \mathrm{~s}$ & $0.876 \mathrm{~s}$ \\
\hline & & \multirow{2}{*}{ Large } & inside the OR & $23.208 \mathrm{~s}$ & $21.708 \mathrm{~s}$ \\
\hline & & & outside the OR & $4.392 \mathrm{~s}$ & $2.004 \mathrm{~s}$ \\
\hline \multirow{8}{*}{$\begin{array}{l}\text { Triangular } \\
90^{\circ}\end{array}$} & \multirow{4}{*}{$10 \mathrm{~mm} / \mathrm{s}$} & \multirow{2}{*}{ Small } & inside the OR & $22.332 \mathrm{~s}$ & $21.648 \mathrm{~s}$ \\
\hline & & & outside the OR & $3.516 \mathrm{~s}$ & $2.508 \mathrm{~s}$ \\
\hline & & \multirow{2}{*}{ Large } & inside the OR & $87.552 \mathrm{~s}$ & $86.196 \mathrm{~s}$ \\
\hline & & & outside the OR & $8.064 \mathrm{~s}$ & $5.604 \mathrm{~s}$ \\
\hline & \multirow{4}{*}{$40 \mathrm{~mm} / \mathrm{s}$} & \multirow{2}{*}{ Small } & inside the OR & $6.288 \mathrm{~s}$ & $5.664 \mathrm{~s}$ \\
\hline & & & outside the OR & $1.644 \mathrm{~s}$ & $0.516 \mathrm{~s}$ \\
\hline & & \multirow{2}{*}{ Large } & inside the OR & $23.316 \mathrm{~s}$ & $21.840 \mathrm{~s}$ \\
\hline & & & outside the OR & $3.672 \mathrm{~s}$ & $1.284 \mathrm{~s}$ \\
\hline
\end{tabular}

